\title{
1 Mechanisms and Designs of Asymmetrical Electrochemical Capacitors
}

2 Bamidele Akinwolemiwa ${ }^{\mathrm{a}}$, Chaohui Wei ${ }^{\mathrm{a}}$, George Z. Chen ${ }^{\mathrm{a}, \mathrm{b}, *}$

$3{ }^{a}$ Department of Chemical and Environmental Engineering, and Centre for Sustainable Energy

4 Technologies, Faculty of Science and Engineering, University of Nottingham Ningbo China, Ningbo

5315100, P. R. China.

$6{ }^{\mathrm{b}}$ Department of Chemical and Environmental Engineering, Faculty of Engineering, University of

7 Nottingham, Nottingham NG7 2RD, UK.

$8 \quad *$ E-mail: george.chen@ nottingham.ac.uk (G. Z. Chen)

9

10 Abstract. Different charge storage mechanisms in electrochemical energy storage devices are reviewed, 11 including non-Faradaic capacitive, Faradaic capacitive, Faradaic non-capacitive, and their combinations. Specifically, Faradaic capacitive (pseudocapacitive) storage and Faradaic non-capacitive

13 (Nernstian) storage are attributed to the transfer of delocalised and localised valence electrons, 14 respectively. Mathematical and graphical expressions of the respective storage performances are 15 presented. The account is made especially for asymmetrical electrochemical capacitors (AECs), 16 supercapattery and supercabattery. Both hypothetical and experimental examples are presented to 17 demonstrate the merits of supercapattery that combines capacitive and Nernstian electrodes. Enhanced 18 storage performance is shown by properly pairing and balancing the properties of the negatrode 19 (negative electrode) and positrode (positive electrode) in the AEC or supercapattery. In addition, the 20 design, laboratory manufacturing and performance of several stacks of bipolarly connected AEC cells 21 are assessed in terms of commercial feasibility and promise.

22 Keywords: Asymmetrical electrochemical capacitors; Supercapattery; Charge storage mechanisms; 23 Pseudocapacitance; Delocalised valence electrons; Nernstian storage 


\section{1. Introduction}

Supercapacitor is the commercial name of electrochemical capacitor (EC) that has attracted exponentially growing interests in both academia and industry. The positrode (positive electrode) and negatrode (negative electrode) of an EC can be made from the same or different materials, corresponding to, respectively, symmetrical or asymmetrical EC [1-3]. Strictly speaking, there is no EC that is symmetrical because even with the same material, the charge storage processes are different at the positrode and negatrode. For example, when charging an EC with activated carbon on both electrodes, anions are stored in the positrode whilst cations in the negatrode, which means asymmetry in the electrical double layer (EDL) structure, charge storage kinetics and specific capacitance. Thus, it can be stated that all known ECs are asymmetrical in nature.

Nevertheless, the scientific rigour is not always followed in research, and a successful advancement in science or technology may also result from initially misinterpreted observations [4]. It is very much a similar story in the research and development of ECs, particularly the asymmetrical device which often has an electrode that is capable of Faradaic charge storage to gain an increased specific capacity of storage. The Faradaic process is known to involve transfer of charges (electrons or ions or both) across the "electrode | electrolyte" interface (EEI). It has been ascribed to Nernst's law concerning a unique electrode potential, $E^{\mathrm{o}}$, although its association with the so called pseudocapacitance in recent years has led to confusion between materials with capacitive and noncapacitive performances. There is no doubt that enhancement in energy storage is the practical purpose in both cases, but clarification of the charge storage mechanisms is necessary so that researchers can inform their industrial colleagues with reliable information about energy storage capacity, speed and cycle life. This article aims to offer some fundamental considerations and practical examples on using both capacitive and non-capacitive materials to fabricate asymmetrical ECs. With particular reference to hybrid devices whose performances follow or do not follow the capacitor equations, the terms of 
1 supercapattery and supercabattery are recommended, respectively, together with correct performance

2 description and analysis [2,3]. Furthermore, device engineering leading to the fabrication of stacked EC

3 cells will be briefly considered. It is acknowledged that the terms "pseudocapacitor" and "hybrid

4 capacitor" and are also used in the literature, but these terms are not the same as supercapattery because

5 the former is still a capacitor and is composed of two different capacitive electrodes. A supercapattery

6 can be composed of two different capacitive electrodes, but also of a capacitive and a Nernstian

7 electrode as explained below in details.

\section{2. Charge storage mechanisms in electrodes}

10 In general, storage mechanisms can be classified as either non-Faradaic capacitive, Faradaic 11 capacitive (pseudocapacitive) or Faradaic non-capacitive (Nernstian) (see Figure 1a) [3]. Based on 12 these mechanisms, the electrochemical properties of electrodes which could be used in the fabrication 13 of ECs can be categorised under any of the four schematic illustrations given in Figure 1b. The 14 schematic cyclic voltammograms of Figure $1 \mathrm{~b}$ represents single electrode characterisations (i.e. 15 collected using the three-electrode cell configuration).

Figure 1(b4) could be used to generally illustrate the electrochemical characteristics of 17 electrodes displaying non-Faradaic capacitive storage i.e. EDL capacitance. This is usually due to the electrostatic separation of electrons and ions at the EEI. Fundamentally, the amount of interfacial charge storage $(Q)$ in these types of electrodes can be correlated with the interfacial capacitance $(C)$ at a given electrode potential $(E)$ by the usual capacitor equation below,

$$
C=\frac{d Q}{d E}=\frac{d Q / d t}{d E / d t}=\frac{i}{v}
$$

where $i$ is the current and $v$ the potential scan rate (for example in cyclic voltammetry) [2]. Note that in practice, Equation (1) is correct only when $C$ remains constant, at least approximately, in the applied 
1 range of potentials. If $C$ varies significantly with potential, Equation (1) is invalid. It is important to

2 note that all capacitive electrodes, either EDL or Faradaic, would give rectangular cyclic

3 voltammograms (CVs) and triangular galvanostatic charging-discharging curves (GCDs). With a

4 replacement of $E$ by the cell voltage, $U$, Equation (1) can be applied for calculation of the cell

5 capacitance, $C_{\text {cell }}$, of an EC constructed from two capacitive electrodes. The maximum energy stored in

6 the EC, $W$ is correlated with $C_{\text {cell }}$ and $U$ by Equation (2).

7

$$
W=0.5 C_{c e l l} U^{2}
$$

8 In Equation (2), $C_{\text {cell }}$ results from the serial connection of the positrode capacitance, $C_{\mathrm{P}}$, and negatrode 9 capacitance, $C_{\mathrm{N}}$, i.e. $1 / C_{\text {cell }}=1 / C_{\mathrm{P}}+1 / C_{\mathrm{N}}$. It should be emphasised that $C_{\text {cell }}$ in Equation (2) should not be replaced by either $C_{\mathrm{P}}$ or $C_{\mathrm{N}}$ because it is practically impossible to store energy in a single electrode without the counter electrode. In other words, energy analysis is only practically meaningful in relation with the cell performance.

As is well known, EDL capacitance is the storage mechanism displayed by many carbon-based electrodes such as: activated carbon (AC), carbon nanotubes (CNTs), aerogels, xerogels, carbon onions, graphite etc. $[5,6]$. As evident from the literature, enhancing the properties of carbon electrodes has undergone vast improvements particularly in the areas of carbon production. For example, high performance electrodes with EDL capacitance have been produced from the reduction of $\mathrm{CO}_{2}$ in high temperature molten salts through the process of electrochemical carbon capture and utilisation $[7,8]$.

In recent year, there have been impressive improvements in commercial applications of electrochemical double layer capacitors (EDLCs). For instance, intra-city electric buses fully powered by EDLCs which use AC electrodes and organic electrolytes are currently in operation (see Figure 2) [9]. These EDLC buses can be fully-recharged in $30 \mathrm{~s}$ to enable a journey about $5 \mathrm{~km}$. Nevertheless, the fast charging of these devices coupled with long cycle lives still drives the commercial desire 24 further for "novel" ECs that can deliver charge for a longer period. This in fact is the principal 
1 motivation behind the adoption of various innovative device engineering strategies in the fabrication of 2 asymmetrical electrochemical capacitors (AECs).

3

The rectangular CV in Figure 1(b4) can be used to describe the electrochemical profile due to either EDL storage or Faradaic capacitive storage i.e. pseudocapacitance [10], which are also characterised by linear or triangular GCDs. Materials which display the Faradaic capacitive or pseudocapacitive storage mechanism can be described with the aid of the semiconductor band model (see Figure $1 \mathrm{c}$ and d) [11].

It is well known that reversible electron transfer reactions of redox active molecules or ions in a liquid electrolyte or confined on the electrode surface can be described by the Nernst equation. In these molecules or ions, the valence electrons are localised at a unique and fixed energy level and can therefore be transferred on the electrode at a fixed potential. However, if the valence electrons are delocalised to a certain degree, such as those in semiconductor materials, e.g. many transition metal oxides (TMOs) and electronically conducting polymers (ECPs), the energy levels of these delocalised valence electrons are no longer a single value but spread over an energy band. As a result, the transfer of these delocalised valence electrons occurs in a continuous range of potentials, instead of a fixed single potential. This energetic feature of delocalised valence electrons is responsible for the flow of the capacitive current over a relatively wide potential range [11]. TMOs, such as $\mathrm{RuO}_{2}, \mathrm{MnO}_{2}, \mathrm{SnO}_{2}$ and their composites with nanostructured carbon materials [12-16] are important examples of electrodes which store charge by the pseudocapacitance mechanism. Also, ECPs such as polypyyrole (PPy), polyaniline (PAn) and poly(3,4-ethylenedioxythiophene) (PEDOT) and their composites with nanostructured carbon materials [17-20] also store charge via pseudocapacitance. Other classes of electrode materials for pseudocapacitive storage such as transition metal dichalcogenides (TMDs) e.g. $\mathrm{MoS}_{2}, \mathrm{WS}_{2}, \mathrm{TiS}_{2}$ have also been investigated [21]. Furthermore, density functional theory calculations have been utilised to characterise the charge storage properties of a wide range of these TMDs in order 
1 to aid in the rational selection of electrode materials for practical applications [22].

The two remaining types of Faradaic storage described below are non-capcacitive and mixed

3

capacitive and non-capacitive. These mechanisms are characterised by peak shaped CVs which could either be reversible or quasi-reversible as deduced from their electrochemical features (see Figure 1b). Electrodes giving rise to peaked shaped CVs without any significant capacitive contribution could be in general called Nernstian electrodes.

Electrodes which store charge via a mixed Nernstian and capacitive mechanism are those that conjointly display marked capacitive and Nernstian features as illustrated in Figure 1(b3). For example PAn nanofibrils typify this property when it is scanned from -0.1 to $1.0 \mathrm{~V}$ vs $\mathrm{Ag} / \mathrm{AgCl}$ (see Figure $3 \mathrm{a}$ ) [23]. Moreover within the potential range 0.2 to $0.7 \mathrm{~V}$ vs $\mathrm{Ag} / \mathrm{AgCl}$, this material displays a capacitive storage mechanism (in this case, pseudocapacitance dominates). Lithiated carbon materials, particularly those with nanostructures accessible by the electrolyte, would also display such properties with the capacitive storage being largely due to EDL capacitance from the carbon electrodes [11]. Accordingly, in calculation of the specific charge of such an electrode $\left(Q_{\mathrm{M}}\right)$, the contributions from both the Nernstian and capacitive storage mechanisms must be considered. This could be achieved by using expressions such as that in Equation (3), which describes the stored charge as due to the Faradaic storage and the EDL capacitance storage mechanisms:

$$
Q_{M}=\frac{Q}{M}=\frac{n F}{M}+A C_{d l} \Delta E
$$

where $Q$ is the Faradaic charge transferred over the applied potential range, $\Delta E, n$ the number of electrons participating in the Faradaic reaction, $M$ the molar mass of the electrode material, $A$ the specific area of the electrode $\left(\mathrm{m}^{2} / \mathrm{g}\right), C_{\mathrm{dl}}$ the capacitance per unit specific area of the electrode material. If the Faradaic charge transfer is capacitive, Equation (3) can be re-written as Equation (4) below for calculation of the specific capacitance of the electrode material, $C_{\mathrm{M}}$. 
$1 \quad C_{M}=\frac{Q}{M \Delta E}=\frac{n F}{M \Delta E}+A C_{d l}$

The Faradaic non-capacitive storage (often referred as battery storage) alone is Nernstian in

3 nature. It involves the exchange of electrons across the EEI at a fixed electrode potential which can be

4 described by the Nernst equation in terms of the mole fraction, $x$, of the reduced sites on the electrode 5 surface.

$$
E=E^{o}+\frac{n F}{R T} \ln \left(\frac{1-x}{x}\right)
$$

7 If the process is reversible i.e. occurring under Nernstian conditions, and assuming that the entire bulk

8 of the material on the electrode undergoes the same redox reaction, the theoretical value of $Q_{\mathrm{M}}$ of the 9 electrode material can be expressed by the Faraday equation [24].

$10 \quad Q_{M}=\frac{n F}{M}$

11 Note that Equation (6) is same as the first term in Equation (3) but it is used independently here. CVs 12 of a Nernstian electrode are typically peak shaped and hence cannot be analysed using any capacitor 13 equations. Instead, the material property of a Nernstian electrode is analysed in terms of $Q_{\mathrm{M}}$. What is 14 not always clearly referenced in the literature is that $Q_{\mathrm{M}}$ is always associated with a fixed potential, $E^{\mathrm{O}}$ 15 (or potentials for reactions involving the transfer of multiple electrons) as defined by Equation (5). 16 (This is in contrast to $C_{\mathrm{M}}$ for a capacitive electrode which is associated with a potential range, $\Delta E$.)

17 Two Nernstian electrodes with different $E^{\mathrm{o}}$ values can form a battery whose theoretical cell 18 voltage equals to the difference between the positrode and negatrode potentials, i.e. $U=E^{\mathrm{o}}{ }_{\mathrm{P}}-E^{\mathrm{o}} \mathrm{N}$. If 19 the specific charges and masses of the positrode and negatrode are $Q_{\mathrm{M}, \mathrm{P}}$ and $m_{\mathrm{P}}$, and $Q_{\mathrm{M}, \mathrm{N}}$ and $m_{\mathrm{N}}$, 20 respectively, then $Q_{\mathrm{M}, \mathrm{P}} \times m_{\mathrm{P}}=Q_{\mathrm{M}, \mathrm{N}} \times m_{\mathrm{N}}=Q_{\text {cell. }}$. The energy stored in the battery, $W$, can be calculated 21 by Equation (7). 
For the practical use in AECs, it is incorrect to consider the ratio $Q / U$ of a Nernstian electrode

3 as capacitance, since the electrode behaviour is fundamentally non-capacitive. Some recent 4 publications have attempted to clarify this unfortunate situation where Nernstian properties are 5 misconstrued as pseudocapacitive properties [2,10,25]. Moreover, fundamental theoretical calculations 6 have been utilised to reveal the basis of the charge storage mechanisms displayed by some electrode 7 materials [26-28].

As can be seen in the applications of EDLCs for relatively short charging time (for example in 9 intra-city buses [9]), it is obvious that ECs with high specific energy (or energy density) are strongly desirable. This is also coupled with the property of high power (speed of charge intake/delivery) which 11 capacitive charge storage could provide in general. Two main strategies used to achieve high energy in 12 EES devices are to hybrid a large charge capacity electrode with a high capacitance electrode [15]. 13 Moreover, due to the dependence of the energy of an EES device on the cell voltage according to either 14 Equation (2) or (7), it is beneficial to use an electrolyte with a high decomposition voltage (or wide electrochemical window) $[29,30]$. Such an electrolyte can be either an organic salt solution or an ionic 16 liquid which is still pending for commercial justification [31]. Alternatively, due to their non17 flammability compared to organic electrolytes, lower viscosity even at relatively high concentrations 18 than ionic liquids, ease of handling, high ionic conductivity and low cost, aqueous electrolytes are always a choice in the fabrication of EES devices [31, 32].

It should be acknowledged that good understanding of the various device engineering strategies 21 is important in order to satisfactorily use aqueous electrolytes (and indeed any other type of electrolyte) 22 in the production of high voltage (and by consequence high energy) ECs. The combination of 23 electrodes that display different storage mechanisms is an important design aspect in the bid for high performance AECs [33]. The main advantage of AECs is that, provided the charge storage mechanisms 
1 of the electrodes are properly accounted for in the cell design, one or more of the properties of energy,

2 power (and even self-discharge) and cycle life could be increased and/or optimised. The advantages

3 and drawbacks of various configurations of AECs are enumerated in the literature [34]. In this report,

4 an attempt is made to clarify how the charge storage mechanisms in different electrodes (as described

5 in Section 2) and cells can be properly characterised, particularly in terms of capacitance and energy.

6 Also, supercapattery and supercabattery which were recently introduced as generic terms for all forms

7 of AECs and other hybrid devices [11, 19, 25] will be discussed based on their observed

8 electrochemical performances.

9 3. Asymmetrical electrochemical capacitors with capacitive electrodes

10 The possible configurations of this class of AECs are the use of two electrodes with EDL 11 capacitance (i.e. EDLC electrodes), two pseudocapacitive electrodes, or the use of an EDLC electrode 12 and a pseudocapacitive electrode.

13 Of particular importance to the fabrication of AECs is the determination of the capacitive 14 potential range (CPR) of each electrode. Within the CPR, all processes on the electrode are 15 electrochemically reversible and capacitive in nature. That is the potential range (window) before the 16 onset of any irreversible reaction of the electrode and/or decomposition of the electrolyte, see Figure $3 \mathrm{~b}$ 17 [35]. The CPR can be determined from the CV of a given "electrode | electrolyte" combination using 18 the following equation,

$$
C P R=E_{P_{i} \max }-E_{N_{i} \max }
$$

where $E_{\mathrm{P}, \max }$ and $E_{\mathrm{N}, \max }$ are maximum positive and negative potentials of the capacitive $\mathrm{CV}$.

21 Figure $3 \mathrm{~b}$ shows the CVs of an AC electrode in different potential ranges recorded in a three-

22 electrode cell containing the aqueous electrolyte of $0.3 \mathrm{~mol} / \mathrm{L} \mathrm{K}_{2} \mathrm{SO}_{4}$. The AC used was Cabot 23 Monarch 1300 pigment black (CMPB) and it was coated on the surface of a graphite disc electrode (0.6 $\mathrm{cm}$ in diameter) [35]. In Figure $3 \mathrm{~b}$, it can be seen that $E_{\mathrm{P}, \max }$ and $E_{\mathrm{N}, \max }$ are $0.9 \mathrm{~V}$ and $-1.3 \mathrm{~V}$, 
1 respectively. Referring to Figure $3 \mathrm{~b}$ and using Equation (8), the CPR of the CMPB electrode in $\mathrm{K}_{2} \mathrm{SO}_{4}$

2 can be calculated as $0.9-(-1.3)=2.2 \mathrm{~V}$. It is worth mentioning that for using the CMPB to make both

3 the positrode and negatrode in a cell, i.e. the so called symmetrical supercapacitor. The CPR is in

4 principle the same as the maximum capacitive voltage (MCV). In such a case, the specific energy of

5 the cell, $W_{\mathrm{M}}$, can be derived from the $C_{\mathrm{M}}$ of the CMPB according to Equation (2) and $C_{\text {cell }} /(2 m)=C_{\mathrm{M}} / 4$

6 where $m$ is the mass of each electrode,

$7 \quad W_{M}=\frac{W}{2 m}=\frac{c_{c e l l} U^{2} / 2}{2 m}=\frac{c_{M} U^{2}}{8}$

It is a common knowledge that a carbon electrode (e.g. AC) could show different interfacial capacitive profiles depending on if it is used on the negatrode or positrode. In other words, the electrostatic attraction of anions to the positrode and that of cations to the negatrode have different 11 capacitances (or capacitive profiles) as can be clearly observed in Figure 3b. This implies that even if 12 the two electrodes of the same material in a given EC have equal masses, such a device is inherently asymmetrical. In fact, it has been explained that ECs with similar electrode material assembled with equal electrode capacitances (e.g. with equal masses), would exhibit different capacitances after extensive cycling [34].

Figure $4 \mathrm{a}$ and $4 \mathrm{~b}$ show CVs collected from the same "electrode | electrolyte" that was used to record the CVs in Figure 3b. The solid curves correspond to a whole range of the potential scan of the single carbon electrode and the whole range can eventually increase to the CPR. The dashed curves correspond to positive (red curve) and negative (blue curve) polarisations of the electrode i.e. the charge profiles of the positrode (with capacitance $C \mathrm{p}$ ) and negatrode (with capacitance $C_{\mathrm{N}}$ ), respectively. $E_{\mathrm{V} 0}$ is the equal potential of both the positrode and negatrode when the cell voltage of the

22 device (two-electrode cell) is $0.0 \mathrm{~V}$. It is also known as the potential of zero voltage (PZV). By defining $U_{\mathrm{P}}=\left(E_{\mathrm{P}}-E_{\mathrm{V} 0}\right)$ and $U_{\mathrm{N}}=\left(E_{\mathrm{V} 0}-E_{\mathrm{N}}\right)$ where $E_{\mathrm{P}}$ and $E_{\mathrm{N}}$ are the positrode and negatrode 
1 potentials, respectively, the capacitance equation based on the principle of conservation of charge $(Q)$

2 can be expressed by Equation (9). Also, since the electrodes in the device are connected in series the

3 cell capacitance, $C_{\text {cell }}$, can be given by Equation (10) whilst the cell voltage, $U$, can be expressed by

4 Equation (11) [36].

6

7

$$
Q=C_{p} U_{P}=C_{N} U_{N} \quad \text { or } \quad U_{N}=U_{P} \frac{C_{P}}{c_{N}}
$$

$$
C_{\text {cell }}=\frac{c_{P} c_{N}}{\left(c_{P}+c_{N}\right)}=\frac{c_{P}}{\left(1+c_{P} / C_{N}\right)}
$$

$$
\boldsymbol{U}=U_{P}+U_{N}=U_{P}\left(1+\frac{c_{P}}{c_{N}}\right)
$$

8 From Equation (9) - (11), it is obvious that an adequate adjustment of the $C_{\mathrm{P}} / C_{\mathrm{N}}$ ratio can extend $U$ of

9 the AEC, but decrease $C_{\text {cell. }}$. Because $W=0.5 C_{\text {cell }} U^{2}$, the loss in $C_{\text {cell }}$ would be compensated by the gain

10 in $W$. Indeed, it was shown that with the CMPB as both the positrode and negatrode, at $C_{\mathrm{P}} / C_{\mathrm{N}}=4 / 3$, the

11 AEC gave the optimal performance at a cell voltage, i.e. the $\mathrm{MCV}$, as high as $1.9 \mathrm{~V}$ in aqueous $\mathrm{K}_{2} \mathrm{SO}_{4}$

12 [35]. In essence, by raising $C_{\mathrm{P}} / C_{\mathrm{N}}$, the negatrode potential as shown in Figure $4 \mathrm{~b}$ was extended to 13 recover what is termed as the "wasted potential" in Figure 4a.

14 It was also shown that the performance of the AEC depended strongly on the $C_{\mathrm{P}} / C_{\mathrm{N}}$ ratio [35].

15 For example as shown in Figure $4 \mathrm{c}$, with $C_{\mathrm{P}} / C_{\mathrm{N}}=1$, the $\mathrm{CV}$ starts showing an additional current near

16 the high voltage end when the cell voltage is greater than $1.6 \mathrm{~V}$, indicating unwanted reactions at the

17 electrodes. The same behaviour is not seen on the CVs in Figure $4 \mathrm{~d}$ with $C_{\mathrm{P}} / C_{\mathrm{N}}=4 / 3$. Figure $4 \mathrm{e}$ plots

18 the electrode potential against the cell voltage and indicates the maximum positrode potential to be 0.91

$19 \mathrm{~V}$ (vs. $\mathrm{Ag} / \mathrm{AgCl}$ ). At $C_{\mathrm{p}} / C_{\mathrm{N}}=1$, it can be seen that the positrode potential increased beyond $0.91 \mathrm{~V}$, 20 leading to inevitable unwanted anodic reaction. Furthermore, as shown in Figure $4 \mathrm{f}$, the device 21 exhibited the optimal capacitance ratio of $C_{\mathrm{P}} / C_{\mathrm{N}}=4 / 3$, optimal cell voltage of $1.9 \mathrm{~V}$, and good stability 22 in 10000 cycles. At other values of $C_{\mathrm{P}} / C_{\mathrm{N}}$ and $U$, e.g. $3: 1$ and $2.0 \mathrm{~V}$, or $1: 1$ and $1.9 \mathrm{~V}$, the cell showed 
1 obvious degradation in cycle stability. More importantly, data analysis confirmed that at $C_{\mathrm{P}} / C_{\mathrm{N}}=4 / 3$,

2 the cell capacitance decreased by only $2 \%$ whereas the specific energy of the cell increased by $38 \%$ 3 [35].

In Equation (11), $U_{\mathrm{P}}$ can extend to the CPR of the positrode. In the case of the AEC with

5 CMPB electrodes in $0.3 \mathrm{~mol} / \mathrm{L} \mathrm{K}_{2} \mathrm{SO}_{4}$, the positrode is the so called "cell voltage limiting electrode"

6 (CVLE). In other words, the MCV of the AEC is limited by the CPR of the positrode [36]. If the

7 negatrode is CVLE, Equation (11) which applies to all AECs can be rearranged as $U=U_{\mathrm{N}}\left(1+C_{\mathrm{N}} / C_{\mathrm{P}}\right)$.

8 This generalisation is best appreciated later from Figure 7a, which illustrates these concepts for

9 capacitive electrodes. From Figure $7 \mathrm{a}$, with $E_{\mathrm{N} 2}>E_{\mathrm{P} 1}$, the positrode is the CVLE. However, if $E_{\mathrm{P} 1}>$

$10 E_{\mathrm{N} 2}$, then the negatrode is the CVLE $[36,37]$. The translation of the CPR into the MCV of a cell has

11 been demonstrated for an EC with activated carbon electrodes and $1 \mathrm{~mol} / \mathrm{L} \mathrm{Li}_{2} \mathrm{SO}_{4}$ which can be

12 operated at an MCV of $2.2 \mathrm{~V}$ for 15000 cycles with negligible capacitance fade [38].

13 In an early example of using Faradaic capacitive or pseudocapacitive materials to build an AEC,

14 the nanocomposites of carbon nanotubes (CNTs) with $\mathrm{SnO}_{2}$ and $\mathrm{MnO}_{2}$ were studied [39]. Figure 5a

15 shows the $\mathrm{CVs}$ of the $\mathrm{MnO}_{2}-\mathrm{CNT}$ positrode and $\mathrm{SnO}_{2}-\mathrm{CNT}$ negatrode in such a device. In such designs,

16 it is important to note and compare the CPRs of the electrodes [37, 39]. As can be seen from Figure 5b,

17 the obtained AECs could work at a high cell voltage up to $1.7 \mathrm{~V}$ in aqueous $2.0 \mathrm{~mol} / \mathrm{L} \mathrm{KCl} \mathrm{[39].}$

18 Combining a non-Faradaic capacitive electrode (e.g. an EDLC electrode) and a Faradaic

19 capacitive or pseudocapacitive electrode into an AEC is a well-known design [33]. This is mostly due

20 to the improved cell capacitance and increased energy (increased voltage) which might be obtained

21 from such devices particularly in aqueous electrolytes. Due to their high polarisability, carbon materials

22 are usually the EDLC electrode of choice in such AECs [40].

ECPs as pseudocapacitive materials have been combined with EDLC materials such as CNTs or

24 AC to fabricate AECs. As was demonstrated recently [36], the performances of this class of AECs are 
1 also sensitive to the $C_{\mathrm{P}} / C_{\mathrm{N}}$ ratio. Figure 6a shows the $\mathrm{CVs}$ of an $\mathrm{AEC}$ of $(-) \mathrm{AC}|\mathrm{HCl}(1.0 \mathrm{~mol} / \mathrm{L})|$

2 PAn-CNT (+). The PAn-CNT positrode was prepared from the co-deposition of CNT and polyaniline.

3 The total deposition charge which is proportional to the mass of film deposited is also shown in Figure

4 6a, together with the electrode capacitance ratio $C_{\mathrm{P}} / C_{\mathrm{N}}$. The bar chart in Figure $6 \mathrm{~b}$ shows the

5 percentage change in the specific energy of the AEC as a function of $C_{\mathrm{P}} / C_{\mathrm{N}}$. It should be pointed out

6 that the capacitance $\left(C_{\mathrm{P}}\right)$ of the PAn-CNT positrode was calculated from rectangular CVs recorded

7 within the CPR, i.e. the potential region for capacitive Faradaic process as shown in Figure 3a [36].

Another important category of AECs includes those that make use of a carbon material as

9 EDLC electrode and a TMO as the pseudocapacitive electrode. Figure , $6 \mathrm{c}$ and $6 \mathrm{~d}$ show the CVs of a cell of (-) $\mathrm{AC}\left|\mathrm{Na}_{2} \mathrm{SO}_{4}(0.5 \mathrm{~mol} / \mathrm{L})\right| \mathrm{MnO}_{2}-\mathrm{CNT}(+)$ and it can be seen that the $\mathrm{MCV}$ of both devices

11 is $2.2 \mathrm{~V}$ when the positrode to negatrode mass ratio $\mathrm{R}(+/-)=2.5$ and 3.0 [41]. This concept of using 12 the mass ratio of the capacitive electrodes in designing such AECs is also derived from the conservation of charge principle in $\mathrm{ECs}$, and $\mathrm{R}(+/-)$ is given below.

$$
\boldsymbol{R}(+/-)=\frac{m_{+}}{m_{-}}=\frac{C_{-} \Delta E_{-}}{C_{+} \Delta E_{+}}
$$

15 Note that in Equation (12), $C_{-}$and $C_{+}$are the specific capacitance of the negatrode and positrode as measured within their CPRs, $\Delta \mathrm{E}_{-}$and $\Delta \mathrm{E}_{+}$which correspond to $U_{\mathrm{N}}$ and $U_{\mathrm{P}}$ in Equation (9)-(11), respectively. Figure 6c and 6d show that both the AECs with $\mathrm{R}(+/-)=2.5$ and 3.0 have an $\mathrm{MCV}$ of 2.0 $\mathrm{V}$. At cell voltages greater than $2.0 \mathrm{~V}$, the positrode potential in both devices exceeded the positive potential limit, 1.2 V vs. NHE, represented by the horizontal line in Figure 6e and 6f, causing irreversible reactions at the positrode. In the GCD test of 10,000 cycles at $1.0 \mathrm{~A} / \mathrm{g}$ and $2.0 \mathrm{~V}$, the AEC with $\mathrm{R}(+/-)=2.5$ displayed better stability than that with $\mathrm{R}(+/-)=3.0$. This highlights the importance of long duration cycling as a means of ascertaining the optimum performance metrics of AECs [41]. 
1 pseudocapacitive electrodes with respect to their performance in AECs is of immense design

2 importance. Therefore, experimental data such as those provided in Figure $7 \mathrm{~b}$ which shows the CPR of

3 some common capacitive electrodes, could aid in the correct selection of electrodes and electrolytes in

4 the fabrication of optimal AECs.

5

6 4. Combining capacitive and Nernstian electrodes: Supercapattery and Supercabattery

To achieve improved energy densities in AECs, there have been numerous reports on the pairing of EDLC or pseudocapacitive electrodes with electrodes displaying non-capacitive Faradaic or

9 Nernstian storage mechanisms [42-44]. Since Nernstian and capacitive electrodes are generally 10 characterised by their peak-shaped (Figure $1 \mathrm{~b} 1$ to $1 \mathrm{~b} 3$ ) and rectangular (Figure 1b4) CVs, respectively, 11 it is necessary to make general descriptions of the cells made from these paired electrodes. Figure 8 12 illustrates schematically the CVs of the negatrode and positrode, and the two-electrode cell of 13 differently paired electrodes. The devices shown are battery (Figure 8a), EC (Figure 8b) and what has 14 been termed as the supercapattery (Figure 8c) [3, 11, 25].

15 In theory, either the capacitive or Nernstian electrode can be used as a positrode or negatrode.

16 Moreover, selection of the positrode or negatrode is usually done with knowledge of the stable 17 potential window of the electrode relative to the electrolyte of choice. In essence, the redox potential of the Nernstian electrode, and the CPR of capacitive electrodes are used to help such selections. It is also important to point out that various attempts have been made to devise a nomenclature that clearly describes these hybrid "supercapacitor-battery" devices [45] which makes use of a Nernstian electrode and a capacitive electrode. For example, in trying to describe various classes of device configurations

22 for practical applications, three different types of hybrids were itemised: (a) discrete supercapacitors externally connected with batteries for load-levelling, (b) use of an internal combustion engine with a battery or supercapacitor for automotive drivetrains, and (c) the incorporation of a faradaic and EDLC 
1 type electrode materials into a single device: which was referred to as asymmetric capacitor devices

2 [34]. Also, in a bid to clearly elucidate the nomenclature, devices which could be classed under (a) and

3 (b) above were called external hybrids, whilst asymmetric capacitor devices were termed as internal

4 serial hybrids [40]. A recent attempt has also been made to classify these devices into "asymmetric

5 devices with or without hybrid behaviour" [46]. The terms pseudocapacitors have also been used to

6 describe some of these devices, particularly those employing new Nernstian electrodes [47-57].

In this report, the terms supercapattery and supercabattery, which have been used to describe the properties of devices incorporating Nernstian and capacitive electrodes $[6,42,58-73]$, are adopted

9 as more concise terms to describe such devices from the standpoint of their electrochemical 10 performances. With this noted, it is worth pointing out that the devices described in Sections 4.1 to 4.3 11 adopt the capacitive electrode as positrode, and the Nernstian electrode as negatrode. Also, the

12 illustrative specification of Li metal or lithiated carbon used as the negatrode (Figure 9a and 9c) would 13 be made clear in the course of the descriptions. This approach is based on and developed from our 14 recent studies on this subject $[11,74]$.

\subsection{Supercapattery (of the first kind).}

This is obtained by combining a non-Faradaic capacitive (i.e. EDLC) electrode with a Nernstian electrode as schematically illustrated in Figure 9a. This class of device can be characterised first by balancing the charge on both the Nernstian and EDLC electrodes. According to Figure 9a, the Nernstian electrode is the negatrode and the non-Faradaic capacitive (EDLC) electrode is the positrode.

21 Thus, $Q_{-}$and $Q_{+}$which are the total charges stored in the negatrode and positrode, respectively, can be used to obtain a balance for the masses of $m_{-}$and $m_{+}$of the negatrode and positrode, respectively. This 23 is shown in Equation 13a and $3 \mathrm{~b}$ below, 


$$
Q_{-}=m_{-} Q_{s p-}=m_{+} C_{s p+} \Delta E_{+}=Q_{+}
$$

$2 \quad \frac{m_{+}}{m_{-}}=\frac{Q_{s p-}}{c_{s p+} \Delta E_{+}}$

3 where $Q_{\mathrm{sp}^{-}}=n F / M$ is the specific charge capacity of the Nernstian negatrode $(\mathrm{C} / \mathrm{g}), M$ the molar mass

4 of the negatrode material, $C_{\mathrm{sp}+}$ the specific capacitance of the EDLC positrode $(\mathrm{F} / \mathrm{g})$ and $\Delta E_{+}$the $\mathrm{CPR}$

5 of the positrode. If the negatrode is Li metal, $M_{\mathrm{Li}}=6.941 \mathrm{~g} / \mathrm{mol}$, and $n=1$. Then $Q_{\mathrm{sp}^{-}}=Q_{\mathrm{sp}, \mathrm{Li}}=n F / M_{\mathrm{Li}}$

$6=13.9 \mathrm{kC} / \mathrm{g}(3861 \mathrm{mAh} / \mathrm{g})$. Assuming that the positrode is $\mathrm{AC}$ with $C_{\mathrm{sp}, \mathrm{C}}=200 \mathrm{~F} / \mathrm{g}$ and $\mathrm{CPR}=U_{\mathrm{P}}=4.0$

$7 \mathrm{~V}$, then $Q_{\mathrm{sp}+}=Q_{\mathrm{sp}, \mathrm{C}}($ specific charge of the EDLC electrode $)=C_{\mathrm{sp}, \mathrm{C}} \times U_{\mathrm{P} .}$ Thus from Equation $(13 \mathrm{~b})$,

$8 m_{+} / m_{-}=m_{\mathrm{C}} / m_{\mathrm{Li}}=Q_{\mathrm{sp}, \mathrm{Li}} /\left(C_{\mathrm{sp}, \mathrm{C}} \times U_{\mathrm{P}}\right)=13900 /(200 \times 4.0)=17.4$ which means that the mass of Li is

9 insignificant compared with that of AC. Accordingly, since the electrochemical profiles of these

10 devices are approximately capacitive (red curve in Figure 9a), it is reasonable to assume an apparent

11 cell capacitance, $C_{\text {cell }}$. Because of the insignificant Li mass, $C_{\text {cell }}$ is approximately equal to that of the

12 AC positrode, $C_{\mathrm{C}}$. Accordingly, the specific capacitance of the cell, $C_{\mathrm{sp}, \mathrm{cell}}$, can be expressed by

13 Equation (14a). In other words the cell capacitance $C_{\text {cell }}$ is determined by the mass of the AC positrode,

$14 m_{\mathrm{C}}$. It is also important to note that due to the presence of the Nernstian electrode there would be a

15 minimum charging voltage $\left(U_{\min }\right)$ to prevent lithiation of the AC positrode. If the maximum charging

16 cell voltage is $U_{\max }$, the specific energy of the supercapattery, $W_{\mathrm{sp}}$, can be expressed as Equation (14b).

$$
C_{\text {spicell }}=\frac{C_{\text {cell }}}{m_{L i}+m_{C}} \approx \frac{C_{C}}{m_{C}}=C_{s p i c}
$$

$18 \quad W_{s p}=\frac{c_{s p, C}}{2}\left(U_{\max }^{2}-U_{\min }^{2}\right)$

19 From this reasoning, using the property of the hypothetical cell given in Figure 8 a with $U_{\max }=4.0 \mathrm{~V}$ 20 and $U_{\min }=0.5 \mathrm{~V}$, and applying Equation (14b), the cell would have a specific energy of $555.6 \mathrm{Wh} / \mathrm{kg}$. 
1 It should also be pointed out that if a lithiated material (e.g. lithiated carbon $\mathrm{LiC}_{\mathrm{x}}$ with $\mathrm{x} \geq 6$ ) is used to

2 replace the Li metal negatrode, then $Q_{\mathrm{sp}-}=Q_{\mathrm{sp}, \mathrm{LiC} 6}=1360 \mathrm{C} / \mathrm{g}$. Correspondingly, from Equation $(13 \mathrm{~b})$

3 the mass ratio becomes $m_{+} / m_{-}=m_{c} / m_{\text {LiC6 }}=1340 /(200 \times 4)=1.675$, this implies that in this case the

4 mass of the $\mathrm{LiC}_{6}$ negatrode cannot be neglected. Also, considering that the supercapattery in Figure 9a

5 still retains capacitive features, from practical considerations an apparent capacitance can be calculated

6 for the $\mathrm{LiC}_{6}$ electrode. Since the change in potential of the negatrode along the potential plateau is very

7 narrow $\approx 0.05 \mathrm{~V}$, the calculated apparent capacitance of the negatrode would be 26800 (F/g) which is

8 extremely higher than the capacitance of the capacitive electrode. Consequently, the capacitance of the

9 cell is limited by that of the capacitive positrode, and the mass of the lithiated carbon negatrode is now

10 significant. If the negatrode mass is $1.0 \mathrm{~g}$, from Equation (14a) $C_{\mathrm{sp}, \text { cell }}=m_{\mathrm{c}} C_{\text {cell }} /\left(m_{\mathrm{c}}+m_{\mathrm{LiC} 6}\right)=(1.675 \times$

$11200) /(1+1.675) \cong 125 \mathrm{~F} / \mathrm{g}$. From Equation $(14 \mathrm{~b})$ the specific energy of the supercapattery with

12 lithiated carbon negatrode then becomes $347.2 \mathrm{Wh} / \mathrm{kg}$.

13 A typical example of experimentally demonstrated supercapatteries that can be characterised

14 following the above analysis is (-) $\mathrm{Li}\left|0.5 \mathrm{~mol} / \mathrm{L} \mathrm{LiClO}_{4}+\mathrm{IL}\right| \mathrm{AC}(+)$ [74]. In this cell, the positrode was the Kuraray $\mathrm{AC}$ with $\mathrm{C}_{\mathrm{sp}}=100 \mathrm{~F} / \mathrm{g}$, and the electrolyte was the solution of $\mathrm{LiClO}_{4}$ and gammabutyrolactone $(\gamma-\mathrm{GBL})$ in an ionic liquid (IL) of 1-butyl-1-methylpyrrolidinium tri(pentafluoroethyl)trifluorophosphate (BMPyrrFAP). The negatrode is Li metal. $W_{\mathrm{sp}}$ of this cell (see Figure $9 \mathrm{~b}$ for its GCD profile) could reach $230 \mathrm{Wh} / \mathrm{kg}$ at a current load of $0.4 \mathrm{~A} / \mathrm{g}$ [74].

In the above analysis, a crucial design strategy is to consider the charge equality between the positrode and negatrode, i.e. Equation (13a), which in turn determines the mass ratio of the two 21 electrodes by Equation (13b). When mass ratio is not far away from 1, the combination of a Nernstian 
1 electrode with a capacitive electrode may lead to non-capacitive cell behaviour. For example, a "dual-

2 ion" cell of (-) $\mathrm{MoS}_{2}-\mathrm{C}|1.0 \mathrm{~mol} / \mathrm{L} \mathrm{NaPF} 6+\mathrm{PC}|$ graphite (+) (PC: propylene carbonate) was recently

3 reported for EES [75]. In this cell, the positrode and negatrode had equal masses, but the authors

4 offered no explanation why this equal mass strategy was applied. The initial reversible charge capacity

5 of the $\mathrm{MoS}_{2}-\mathrm{C}$ negatrode was measured to be ca. $170 \mathrm{mAh} / \mathrm{g}(612 \mathrm{C} / \mathrm{g})$, resulting from $\mathrm{Na}^{+}$ion

6 intercalation. The graphite positrode could be capacitive to make this cell a supercapattery. If so,

7 assuming $U_{\mathrm{p}}=2 \mathrm{~V}$ and $C_{\mathrm{sp}, \mathrm{C}}=50 \mathrm{~F} / \mathrm{g}$ for the graphite electrode, the $m_{+} / m_{-}=m_{\text {graphite }} / m_{\mathrm{MoS2}-\mathrm{C}}=$

$8612 /(2 * 50)=6.12$. Thus, it is not surprising that the behaviour of the reported $\mathrm{MoS}_{2}-\mathrm{C} \mid$ graphite cell

9 deviated significantly from being capacitive, particularly when the cell was being charged as shown by

10 the GCDs in Figure 10. However, these GCDs are also not the same as that of a conventional

11 rechargeable battery. Indeed as was reported, the graphite positrode functioned as the host for

12 intercalation of the $\mathrm{PF}_{6}{ }^{-}$ion, making the cell a "dual-ion" cell in which both capacitive and Nernstian

13 storage mechanisms may co-exist. Particularly, it can be seen in Figure 10 that the discharging GCDs

14 are approximately linear and hence apparently capacitive, but the charging GCDs are non-linear. Thus,

15 the energy analysis of this dual-ion cell cannot use Equations (7) and (14b) which are only valid for

16 linear GCDs. Instead, integration of the GCD using Equation (15) below is needed to calculate the

17 energy, which actually corresponds to the area under the GCD, for both charging and discharging.

$$
W=i \int E d t
$$

19 Following the principle of Equation (15), it can be seen from Figure 10b that the energy efficiency of

20 this dual-ion cell was lower than $50 \%$. It is anticipated that the cell could have performed better if the 21 cell design had taken charge balance into consideration so that an appropriate electrode mass ratio can 22 be applied, instead of simply equal mass. 


\section{4.2. Supercapattery (of the second kind).}

This can be designed by combining a Faradaic capacitive (pseudocapacitive) electrode with a

3 Nernstian electrode. This class of device, illustrated in Figure 9c, also has approximate capacitive

4 profiles (red curve in Figure 9c). It should also be noted that in this type of device, the

5 pseudocapacitive electrode is operated at a higher potential albeit with a narrower $\Delta E$ than that of the

6 EDL electrode. For example in the hypothetical cell of Figure 9c, $\Delta E=(4.5-3.5)=1.0 \mathrm{~V}$. In general,

7 they can still be analysed in much the same way as the supercapattery explained in Section 4.1.

8 Consider a pseudocapacitive positrode with a mass of $m_{+}=m_{\text {pseudo }}$ and specific capacitance of $C_{\text {sp,pseudo }}$

$9=500 \mathrm{~F} / \mathrm{g}$. Accordingly, if the negatrode is Li metal with a mass of $m_{-}=m_{\mathrm{Li}}$, then from Equations

10 (13a) and $(13 \mathrm{~b}), m_{+} / m_{-}=m_{\mathrm{pseudo}} / m_{\mathrm{Li}}=13900 /(500 \times 1.0)=27.8$. This again implies that the cell

11 capacitance can be defined in terms of the mass of the pseudocapacitive positrode. That is from

12 Equation (14a), $C_{\mathrm{sp} \text {,cell }} \approx m_{\mathrm{pseudo}} \times C_{\text {cell }}=C_{\mathrm{sp} \text {,pseudo. }}$. For this cell $U_{\max }=4.5 \mathrm{~V}$, and $U_{\min }=3.5 \mathrm{~V}$, then

13 from Equation (14b), $W_{\mathrm{sp}}=555.5 \mathrm{Wh} / \mathrm{kg}$ for the supercapattery described in Figure 9c.

Also, if the negatrode is a lithiated carbon with $Q_{\mathrm{sp}, \mathrm{LiC} 6}=1340 \mathrm{C} / \mathrm{g}$, then the mass ratio $m_{+} / m_{-}=$ $m_{\mathrm{pseudo}} / m_{\mathrm{LiC} 6}=1340 /(500 \times 1) \approx 2.68$, implies that the mass of the negatrode cannot be neglected. It

should also be noticed that the apparent capacitance of the Li negatrode is very high compared to the capacitance of the pseudocapacitive positrode. Consequently, the capacitance of this class of supercapattery is limited by the mass of the pseudocapacitive positrode. Assuming a mass of $1.0 \mathrm{~g}$ for the lithiated carbon negatrode, $C_{\mathrm{sp}, \text { cell }}=m_{\mathrm{pseudo}} \times C_{\text {cell }} /\left(m_{\mathrm{pseudo}}+m_{\mathrm{LiC} 6}\right)=(2.68 \times 500) /(2.68+1)=364.1$

F/g. As such from Equation (14b) with $U_{\max }=4.5 \mathrm{~V}$ and $U_{\min }=3.5 \mathrm{~V}, W_{\mathrm{sp}}=404.6 \mathrm{Wh} / \mathrm{kg}$. Figure $9 \mathrm{~d}$ which shows the GCD profile for the cell of (-) $\mathrm{Li} \mid$ aqueous electrolyte $\mid$ solid electrolyte $\mid \mathrm{MnO}_{2}(+)$ exemplifies such a supercapattery which uses a pseudocapacitive positrode and a Li metal negatrode. 
1 The specific energy of this cell as derived from the GCD measurements was $114 \mathrm{Wh} / \mathrm{kg}$ at a maximum

2 cell voltage of $4.3 \mathrm{~V}$ and a current load of $0.255 \mathrm{~mA} / \mathrm{cm}^{2}[76]$.

3

4

5

\subsection{Supercabattery}

Many battery electrode materials, particularly nanostructured, behave quite differently from the electrochemical performance of Li metal or lithiated carbons. The difference is typically reflected by these materials having redox potentials more positive than that of $\mathrm{Li}_{\mid} \mathrm{Li}^{+}$, and a highly sloped potential

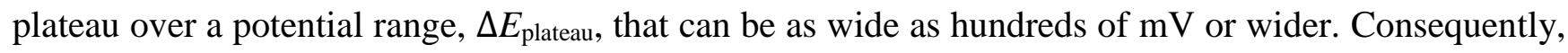

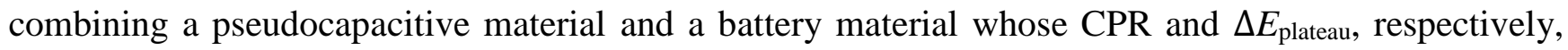
are comparable would result in GCD profiles similar to the one shown in Figure 9e (red GCD curve for device). $U_{\min }$ in this case could be close to zero.

Fundamentally, such devices would behave like batteries and their performances should be expressed as charge capacity, instead of capacitance. In essence, the capacitor concept and equations cannot be used in analysing such devices whose energy capacity should be calculated using Equation (15). The term supercabattery has thus been proposed to describe such devices in which both capacitive and Nernstian storage mechanisms co-exist. For example, the recently reported cells of (-) $\mathrm{Li}_{4} \mathrm{Ti}_{5} \mathrm{O}_{12} \mathrm{I}$ $\mathrm{Li}^{+} \mid \mathrm{AC}(+)$ and (-) $\mathrm{AC}\left|\mathrm{Li}^{+}\right| \mathrm{LiMn}_{2} \mathrm{O}_{4}(+)$ [75] performed very much like the supercabattery. In fact, there are many reported EES cells that employ nanostructured Nernstian materials, such as $\mathrm{NiO}$ and some other transition metal oxides, and behave in the same or similar way as a supercabattery. However, these cells were unfortunately claimed to be pseudocapacitors or hybrid capacitors as reviewed recently $[10,11,25]$. Because the number of published studies on such Nernstian nanomaterials is very large, the topic deserves a separate and more comprehensive account. We believe supercabattery would be a suitable generic and also specific term to clarify the confusion and focus research attention on the great EES potentials of these materials and related hybrid devices. 


\section{5. Device engineering considerations}

3

4

5

In the lab-based design of commercially viable ECs, it is important to optimise all facets of the device fabrication ranging from electrode preparation to cell assembly. Important designs of commercial-scale AEC prototypes include the cell stack using bipolar plates which function as both the current collector and physical separator between neighbouring cells. This design of AECs makes use of the concept of internal serial connections of individual EC cells.

The photographs in Figure $11 \mathrm{a}$ and $11 \mathrm{~b}$ were taken from a $20 \mathrm{~V}$ AEC stack with bipolarly connected cells of (-) CMPB | aqueous $3.0 \mathrm{~mol} / \mathrm{L} \mathrm{KCl} \mathrm{|} \mathrm{PPy-CNT} \mathrm{(+)} \mathrm{[78].} \mathrm{The} \mathrm{bipolar} \mathrm{plates} \mathrm{in} \mathrm{the}$ stack were Ti foils $(0.1 \mathrm{~mm}$ in thickness). Ti was selected due its high mechanical strength and conductivity at low volume and mass and excellent resistance to the corrosion attack by aqueous chloride solutions. In Figure 11c, the rubber sealing washer aids the leak-proof and insulating interconnection between neighbouring Ti bipolar plates, whilst the entire design can be sealed by screwing together the arrangement as shown in Figure 11b.

It should be pointed out that the use of the cell stack with bipolar plates provides a space efficient fabrication of commercial ECs. For example, if $\mathrm{N}$ discrete ECs were to be connected together externally, the number of individual current collectors required is $2 \times \mathrm{N}$. However, in the cell stack with bipolar plates, $\mathrm{N}+1$ current collectors in total are utilised.

More importantly, the bipolar stack design can also be easily adopted for commercial manufacturing because the bipolar plates can be easily coated with the active materials by painting (see Figure 11b) or screen printing with better control of the mass and dimension of the coating[46, 47] [78, 79]. Screen printing is a well-established industrial technique and has been used to print the CMPB on one side of the porous membrane (separator) and the PPy-CNT or PAn-CNT composite on the Ti foil bipolar plate [79]. Figure 12 shows the result from screen printing of the PPy-CNT composite on the 
1 Ti bipolar plate. A stack of 2 cells was assembled, giving rise to a $3.0 \mathrm{~V}$ cell voltage as shown in Figure

$212 \mathrm{c}$ which confirm fairly satisfactory capacitive performance [79].

3 In another design of a $15 \mathrm{~V}$ stack of bipolarly connected 10 AEC cells of (-) $\mathrm{SnO}_{2}-\mathrm{CNT} \mid 1.0$

$4 \mathrm{~mol} / \mathrm{L} \mathrm{Na}_{2} \mathrm{SO}_{4} \mid \mathrm{MnO}_{2}-\mathrm{CNT}(+)$, the active material was manually rolled into free-standing thin films

5 of 0.30 to $0.35 \mathrm{~mm}$ in thickness $[39,79]$.

. Therefore, the stack was conveniently assembled by placing each component layer on top of

7 another layer, following the order of (1) negative end plate, (2) negatrode layer, (3) membrane

8 separator, (4) positrode layer, (5) bipolar plate, (6) repeating (2) to (5) to a designated number of times

9 (cycles), and (7) finally positive end plate. Because manual rolling corresponds to the established industrial technique of roller pressing, this method of making free standing films of active materials can

11 be particularly suitable to fit into an automated production line, promising a great industrial production 12 potential.

It is acknowledged that in current literatures, much less has been reported on device design and 14 manufacturing engineering of ACEs in comparison with that on material synthesis and analysis. 15 However, this area of research and development is undoubtedly crucial in commercialisation of ACEs. 16 It is hoped that the above discussed device designs, although still primitive in nature, can form the basis 17 to support future commercial exploration, optimisation and scale-up of AECs through modern 18 industrial techniques.

\section{Conclusions}

Electrochemical energy storage (EES) can be achieved via non-Faradaic capacitive, Faradaic capacitive, and Faradaic non-capacitive mechanisms and their combinations. Specifically, the origins of

23 Faradaic capacitive (pseudocapacitive) storage and Faradaic non-capacitive (Nernstian) storage can be attributed to the transfer of delocalised and localised valence electrons, respectively. These mechanisms 
1 can be mathematically and graphically expressed in terms of electrochemical characteristics.

2 Asymmetrical electrochemical capacitors (AECs) and other hybrid devices in the generic terms of

3 supercapattery and supercabattery can offer enhanced energy storage performance. Correct

4 understanding of the storage mechanism can help design optimal AECs and supercapatteries via

5 appropriate pairing and balancing of the properties of the positrode and negatrode. In particular, by

6 utilising the correlations of the charge capacity with other properties of the electrode materials such as

7 mass, specific capacitance and capacitive potential range, enhanced device performance can be

8 achieved. This is demonstrated by both hypothetical and experimental examples of supercapattery

9 which combines the merits of both capacitive and Nernstian materials. Commercial feasibility and

10 promises have been analysed and discussed through the design, laboratory manufacturing and

11 performance test of several stacks of bipolarly connected AEC cells, calling for further research and

12 industrial efforts.

\section{Acknowledgments}

15 The authors thank the Ningbo Municipal Government for financial support via the 3315 Plan and the IAMET Special Fund (2014A35001-1), and the International Doctoral Innovation Centre of the

17 University of Nottingham Ningbo China for PhD Scholarships to B. A. and C.W.

\section{REFERENCES}

21 [1] B.E. Conway, J. Electrochem. Soc., 138 (1991) 1539-1548.

22 [2] G.Z. Chen, Prog. Nat. Sci.: Mater. Int., 23 (2013) 245-255.

23 [3] L. Guan, L. Yu, G.Z. Chen, Electrochim. Acta, 206 (2016) 464-478.

24 [4] J.I. Seeman, S. Cantrill, Nat. Chem., 8 (2016) 193-200.

25 [5] T. Chen, L. Dai, Mater. Today, 16 (2013) 272-280.

26 [6] W. Gu, G. Yushin, WIREs: Energy and Environment, 3 (2014) 424-473.

27 [7] H.V. Ijije, R.C. Lawrence, G.Z. Chen, RSC Adv., 4 (2014) 35808-35817. 
[8] B. Deng, Z. Chen, M. Gao, Y. Song, K. Zheng, J. Tang, W. Xiao, X. Mao, D. Wang, Faraday Discuss., 190 (2016) 241-258.

3 [9] B. Akinwolemiwa, L. Yu, D. Hu, X. Jin, J.M. Slattery, G.Z. Chen, Chem. Commun., 52 (2016) 4 12538-12554.

[10] T. Brousse, D. Bélanger, J.W. Long, J. Electrochem. Soc., 162 (2015) A5185-A5189.

[11] G.Z. Chen, Int. Mater. Rev., 62 (2017) 173-202.

[12] A. Singh, A. Chandra, Sci. Rep., 5 (2015).

[13] X. Jin, W. Zhou, S. Zhang, G.Z. Chen, Small, 3 (2007) 1513-1517.

[14] J. Zhang, J. Jiang, H. Li, X. Zhao, Energ Environ. Sci., 4 (2011) 4009-4015.

[15] B. Conway, W. Pell, J. Solid State Electrochem., 7 (2003) 637-644.

[16] N. L. Wu, C. Y. Han, S. Kuo, J. Power Sources, 109 (2002) 418-421.

[17] C. Peng, Z. Zhang, D. Jewell, G.Z. Chen, Prog.Nat. Sci., 7 (2008) 002.

[18] G.A. Snook, P. Kao, A.S. Best, J. Power Sources, 196 (2011) 1-12.

[19] L. Yu, G.Z. Chen, J. Power Sources, 326 (2016) 604-612.

[20] M.J. Bleda-Martínez, C. Peng, S. Zhang, G.Z. Chen, E. Morallón, D. Cazorla-Amorós, J. Electrochem.Soc., 155 (2008) A672-A678.

[21] M.A. Bissett, S.D. Worrall, I.A. Kinloch, R.A.W. Dryfe, Electrochim. Acta, 201 (2016) 30-37.

[22] X. Cong, C. Cheng, Y. Liao, Y. Ye, C. Dong, H. Sun, X. Ji, W. Zhang, P. Fang, L. Miao, J. Jiang, J. Phys. Chem. C, 119 (2015) 20864-20870.

[23] C. Peng, D. Hu, G.Z. Chen, Chem. Comm., 47 (2011) 4105-4107.

[24] A.J. Bard, L.R. Faulkner, Electrochemical Methods, 2, Wiley, (2001).

[25] B. Akinwolemiwa, C. Peng, G.Z. Chen, J. Electrochem. Soc., 162 (2015) A5054-A5059.

[26] B. Zhang, X. Ji, K. Xu, C. Chen, X. Xiong, J. Xiong, Y. Yao, L. Miao, J. Jiang, Electrochim. Acta, 217 (2016) 1-8.

[27] X. Ji, K. Xu, C. Chen, B. Zhang, H. Wan, Y. Ruan, L. Miao, J. Jiang, J. Mater. Chem. A, 3 (2015) 9909-9914.

[28] X. Ji, K. Xu, C. Chen, B. Zhang, Y. Ruan, J. Liu, L. Miao, J. Jiang, Phys. Chem. Chem. Phys., 18 (2016) 4460-4467.

[29] L. Suo, O. Borodin, T. Gao, M. Olguin, J. Ho, X. Fan, C. Luo, C. Wang, K. Xu, Science, 350 (2015) 938-943.

[30] D.W. Lawrence, C. Tran, A.T. Mallajoysula, S.K. Doorn, A. Mohite, G. Gupta, V. Kalra, J. Mater. Chem. A, 4 (2016) 160-166.

[31] L. Xia, L. Yu, D. Hu, G.Z. Chen, Mater. Chem. Front., (2017).

[32] F. Béguin, V. Presser, A. Balducci, E. Frackowiak, Adv. Mater., 26 (2014) 2219-2251.

[33] J.W. Long, D. Bélanger, T. Brousse, W. Sugimoto, M.B. Sassin, O. Crosnier, MRS Bull., 36 (2011) 513-522.

[34] W.G. Pell, B.E. Conway, J. Power Sources, 136 (2004) 334-345.

[35] J.H. Chae, G.Z. Chen, Electrochim. Acta, 86 (2012) 248-254.

[36] C. Peng, S. Zhang, X. Zhou, G.Z. Chen, Energ Environ. Sci., 3 (2010) 1499-1502.

[37] Z. Dai, C. Peng, J.H. Chae, K.C. Ng, G.Z. Chen, Sci. Rep., 5 (2015) 9854.

[38] K. Fic, G. Lota, M. Meller, E. Frackowiak, Energ Environ. Sci., 5 (2012) 5842-5850.

[39] K.C. Ng, S. Zhang, C. Peng, G.Z. Chen, J. Electrochem. Soc., 156 (2009) A846-A853.

[40] D. Cericola, R. Kötz, Electrochim. Acta, 72 (2012) 1-17.

[41] L. Demarconnay, E. Raymundo-Pinero, F. Béguin, J. Power Sources, 196 (2011) 580-586.

[42] H. Shao, N. Padmanathan, D. McNulty, C. O' Dwyer, K.M. Razeeb, ACS Appl. Mater. Interfaces, 8 (2016) 28592-28598.

[43] E. Zhang, Y. Ni, RSC Adv., 6 (2016) 106465-106472.

[44] K.K. Lee, W.S. Chin, C.H. Sow, J. Mater. Chem. A, 2 (2014) 17212-17248. 
[45] J. Lee, S. Choudhury, D. Weingarth, D. Kim, V. Presser, ACS Appl.Mater. Interfaces, 8 (2016) 23676-23687.

[46] S. Roldan, D. Barreda, M. Granda, R. Menendez, R. Santamaria, C. Blanco, Phys. Chem. Chem. Phys., 17 (2015) 1084-1092.

[47] H. Wang, H.S. Casalongue, Y. Liang, H. Dai, J. Am. Chem. Soc., 132, 7472-7477 (2010).

[48] H. Li, M. Yu, F. Wang, P. Liu, Y. Liang, J. Xiao, C. Wang, Y. Tong, G. Yang, Nat. Commun., 4 (2013) 1894.

[49] H.Y. Lee, S. Kim, H.Y. Lee, Electrochem. Solid State Lett., 4 (2001) A19-A22.

[50] X.-H. Xia, J.-P. Tu, X.-L. Wang, C.-D. Gu, X.-B. Zhao, Chem. Commun., 47 (2011) 5786-5788.

[51] K.-H. Chang, C.-C. Hu, C.-M. Huang, Y.-L. Liu, C.-I. Chang, J. Power Sources, 196 (2011) 23872392.

[52] J. Duay, E. Gillette, R. Liu, S.B. Lee, Phys. Chem. Chem. Phys., 14 (2012) 3329-3337.

[53] D. Sarkar, G.G. Khan, A.K. Singh, K. Mandal, J. Phys. Chem. C, 117 (2013) 15523-15531.

[54] H.-Y. Hsu, K.-H. Chang, R.R. Salunkhe, C.-T. Hsu, C.-C. Hu, Electrochim. Acta, 94 (2013) 104112.

[55] T. Brezesinski, J. Wang, S.H. Tolbert, B. Dunn, Nat. Mater., 9 (2010) 146-151.

[56] M. Liu, J. Chang, J. Sun, L. Gao, RSC Adv., 3 (2013) 8003-8008.

[57] Z. Jian, V. Raju, Z. Li, Z. Xing, Y.S. Hu, X. Ji, Advanced Funct. Mater., 25 (2015) 5778-5785.

[58] W.-j. Huang, T. Chang-Hsien, Y.-J. Liou, (2015) US Patent, 9171678 B2.

[59] M.W.-S. Zhao L-P, Wang H-Y, Qi L., Acta Physico-Chimica Sinica, 33 (2017) 787-794.

[60] A.A. Alguail, A.H. Al-Eggiely, B.N. Grgur, J. Saudi Chem. Soc..

[61] S. Vijayakumar, S. Nagamuthu, K.-S. Ryu, Electrochim. Acta, 238 (2017) 99-106.

[62] Y.F. Huang, W.H. Ruan, D.L. Lin, M.Q. Zhang, ACS Appl.Mater. Interfaces, 9 (2017) 909-918.

[63] S. Vijayakumar, S. Nagamuthu, S.-H. Lee, K.-S. Ryu, Int. J. Hydrogen Energy, 42 (2017) 31223129.

[64] N. Padmanathan, H. Shao, D. McNulty, C. O'Dwyer, K.M. Razeeb, J. Mater. Chem. A, 4 (2016) 4820-4830.

[65] X. Liang, W. Pan, K. Chen, D. Xue, Chin. J. Appl. Chem., 33 (2016) 867-875.

[66] K. Chen, D. Xue, J. Mater. Chem. A, 4 (2016) 7522-7537.

[67] D.G. Gromadskyi, J. Chem. Sci., 128 (2016) 1011-1017.

[68] G. Hatui, G. Chandra Nayak, G. Udayabhanu, Y.K. Mishra, D.D. Pathak, New J. Chem., 41 (2017) 2702-2716.

[69] F.N. Ajjan, N. Casado, T. Rebis, A. Elfwing, N. Solin, D. Mecerreyes, O. Inganas, J. Mater. Chem. A, 4 (2016) 1838-1847.

[70] M. Zeiger, N. Jackel, V.N. Mochalin, V. Presser, J. Mater. Chem. A, 4 (2016) 3172-3196.

[71] S. Admassie, F.N. Ajjan, A. Elfwing, O. Inganas, Mater. Horiz., 3 (2016) 174-185.

[72] M. R. Lukatskaya, B. Dunn, Y. Gogotsi, Nat. Commun. 7 (2016) 12647.

[73] H. Zhou, X. Wang, E. Sheridan, H. Gao, J. Du, J. Yang, D. Chen, J. Electrochem.Soc., 163 (2016) A2618-A2622.

[74] L. Yu, G.Z. Chen, Faraday Discuss., 190 (2016) 231-240.

[75] L. Zhao, L. Qi, H. Wang, RSC Adv., 5 (2015) 15431-15437.

[76] S. Makino, Y. Shinohara, T. Ban, W. Shimizu, K. Takahashi, N. Imanishi, W. Sugimoto, RSC Adv., 2 (2012) 12144-12147.

[77] D. Cericola, P. Novák, A. Wokaun, R. Kötz, J. Power Sources, 196 (2011) 10305-10313.

[78] X. Zhou, C. Peng, G.Z. Chen, AIChe J., 58 (2012) 974-983.

[79] X. Zhou, G.Z. Chen, J. Electrochem, 18 (2012) 548-565. 
(a)

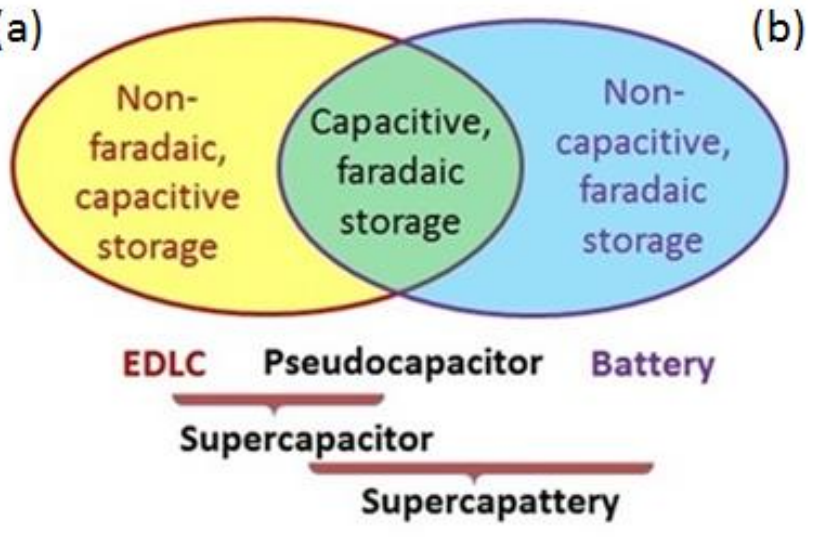

(b)

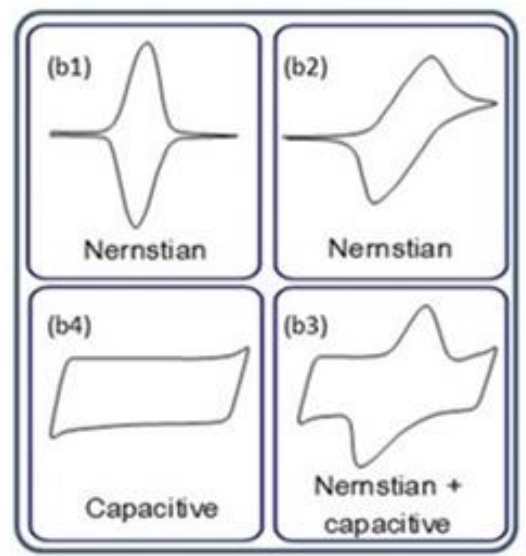

(c)

(d)
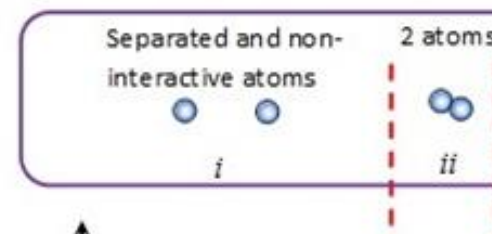

5 atoms
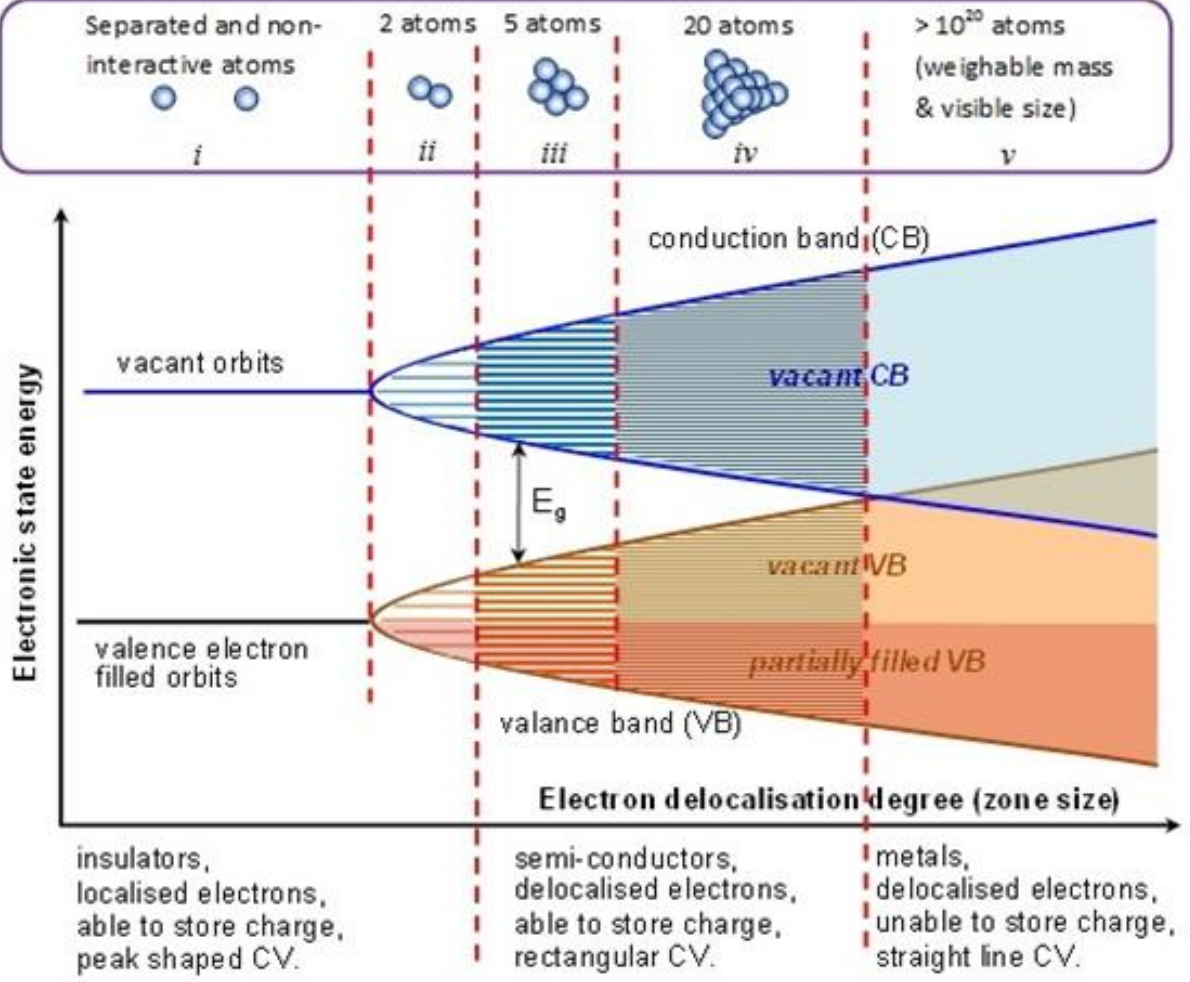
able to store charge able to store charge rectangular $\mathrm{CV}$.

delocalised electrons.

unable to store cha
straight line $\mathrm{CV}$.

Figure 1: (a) Charge storage mechanisms for electrochemical energy storage and their possible device classification [3]. (b) Schematic representations of the voltammetric features for Nernstian (b1, b2), mixed Nernstian and capacitive (b3) and capacitive (b4) charge storage mechanisms. (c) Schematic illustrations of the band model for chemical bonding (c) between metal atoms that are separated and non-interactive (i), and forming clusters of 2 (ii), 5 (iii), 20 (iv) and $10^{20}$ (v) atoms. (d) The corresponding energy levels of the valence electrons as a function of the degree (or zone size) of delocalisation of valence electrons in the respective clusters of metal atoms [11].[11,24] 

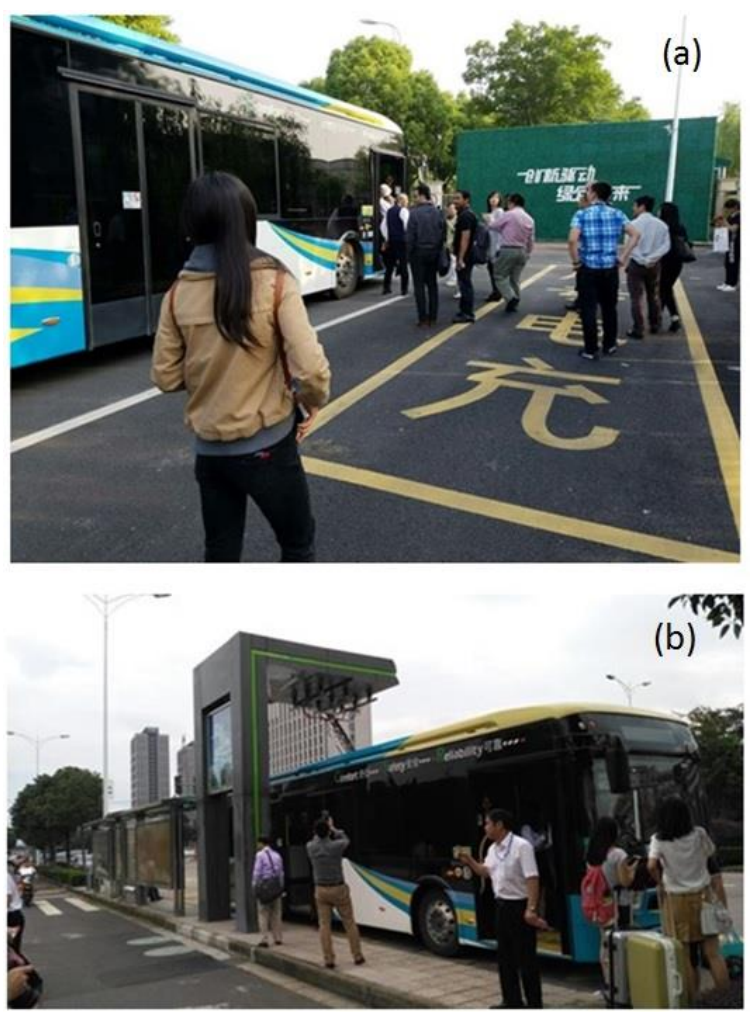

2 Figure 2: (a) Intra-city ride on an electric bus fully powered by supercapacitors (EDL capacitors) [9].

3 (b) A supercapacitor bus is being charged at one of the stops along the bus route.

(a)

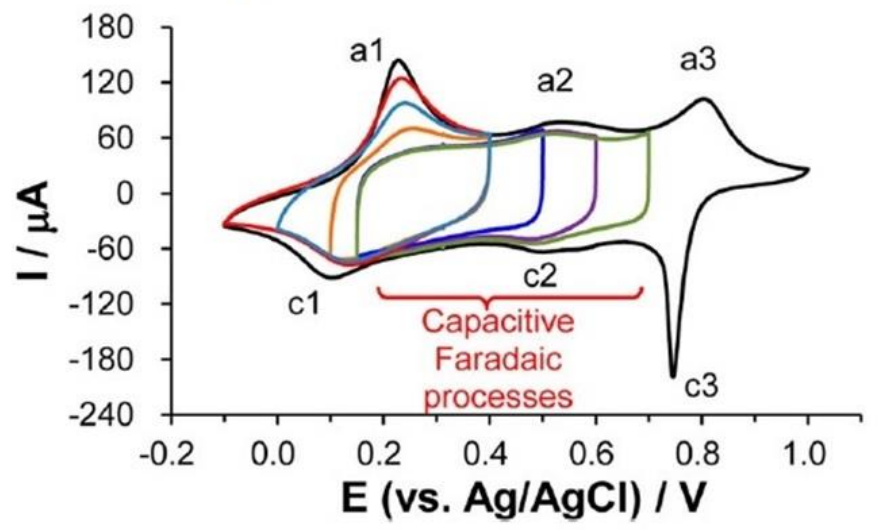

(b)

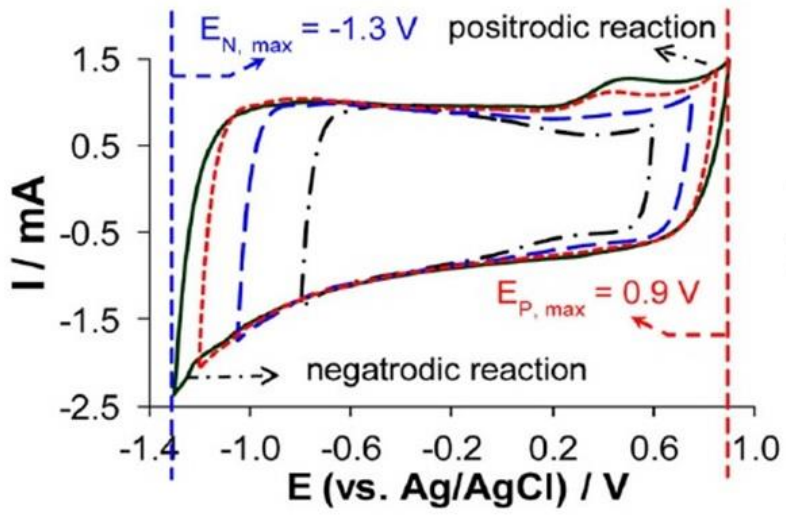

8 Figure 3: $\mathrm{CVs}$ of (a) a PAn-CNT film in $1.0 \mathrm{~mol} / \mathrm{L} \mathrm{HCl}$ showing both the capacitive and mixed 9 Nernstian and capacitive potential ranges [23], and (b) a CMPB (2.5 mg) coating in $0.3 \mathrm{~mol} / \mathrm{L} \mathrm{K}_{2} \mathrm{SO}_{4}$ 10 [35] showing the dominant capacitive features in the explored potential ranges. 

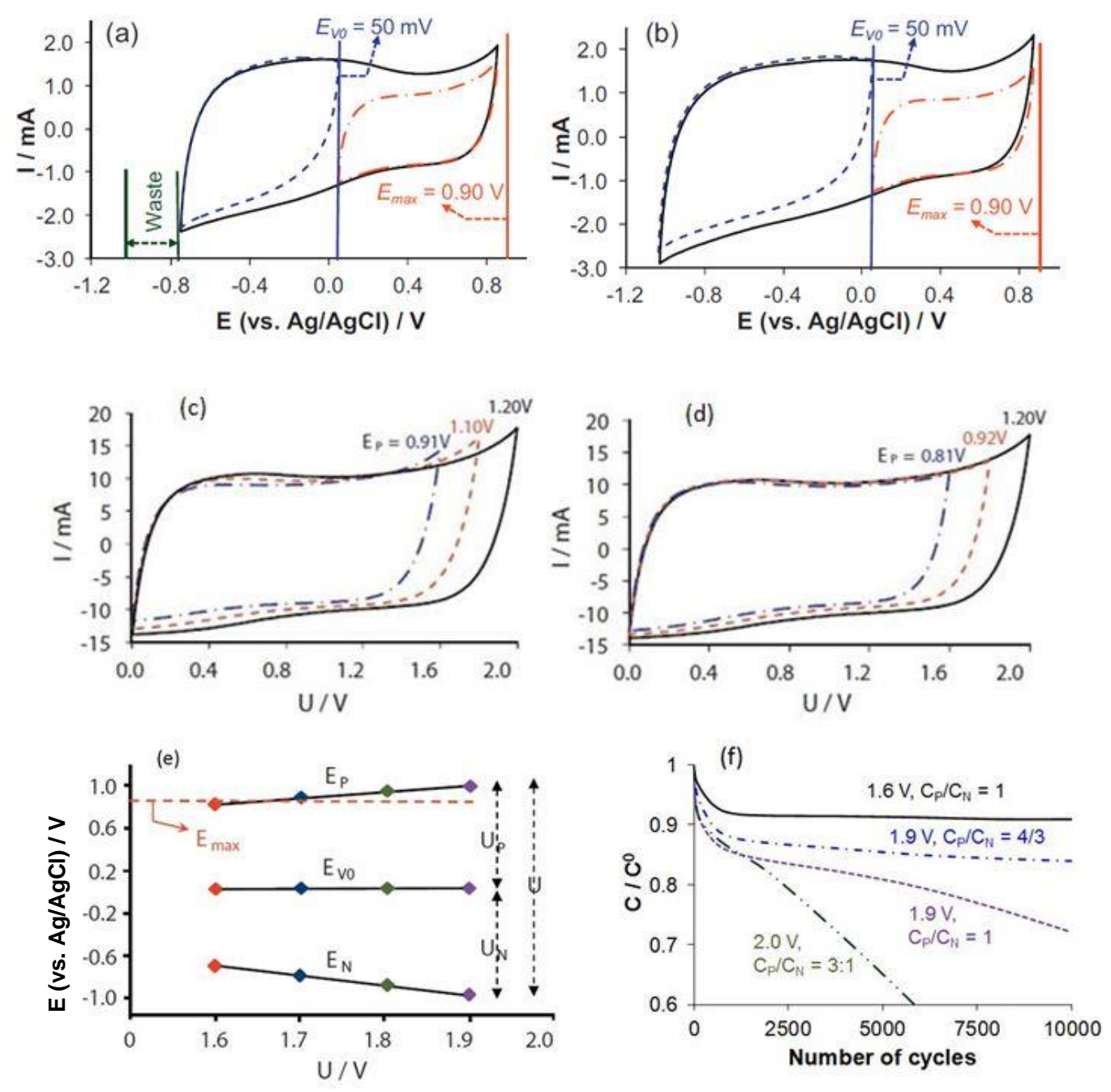

3 Figure 4: $(\mathbf{a}, \mathbf{b}) \mathrm{CVs}$ showing the variation of capacitive feature in different potential ranges of the 4 CMPB electrode in $0.3 \mathrm{~mol} / \mathrm{L} \mathrm{K}_{2} \mathrm{SO}_{4}$. (c,d) $\mathrm{CVs}$ of $\mathrm{AECs}$ with $\mathrm{CMPB}$ on both the positrode and 5 negatrode at $C_{\mathrm{P}} / C_{\mathrm{N}}=1$ (c) and $4 / 3$ (d), respectively. (e) Plots of electrode potential against cell voltage 6 of an AEC with $\mathrm{CMPB}$ on both the positrode and negatrode at $C_{\mathrm{P}} / C_{\mathrm{N}}=1$. (f) Cyclic stability (up to 710000 cycles) of $\mathrm{AECs}$ at the indicated $C_{\mathrm{P}} / C_{\mathrm{N}}$ ratios and cell voltages [35]. 

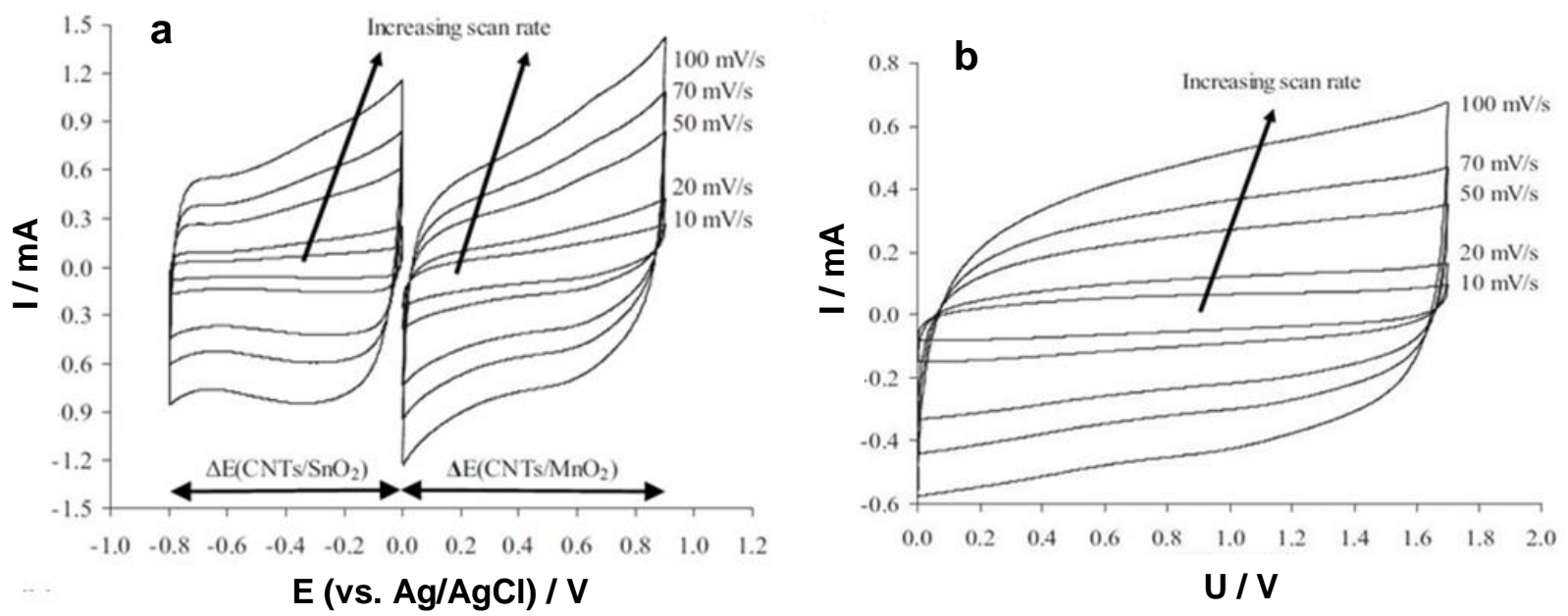

9 Figure 5: $\mathrm{CVs}$ of (a) $\mathrm{SnO}_{2}-\mathrm{CNT}$ and $\mathrm{MnO}_{2}-\mathrm{CNT}$ composites in $2.0 \mathrm{~mol} / \mathrm{L} \mathrm{KCl}$, and (b) the $\mathrm{AEC}$ of $(-)$ $10 \quad \mathrm{SnO}_{2}-\mathrm{CNT}|\mathrm{KCl}(2 \mathrm{~mol} / \mathrm{L})| \mathrm{MnO}_{2}-\mathrm{CNT}(+)[39]$.

11 

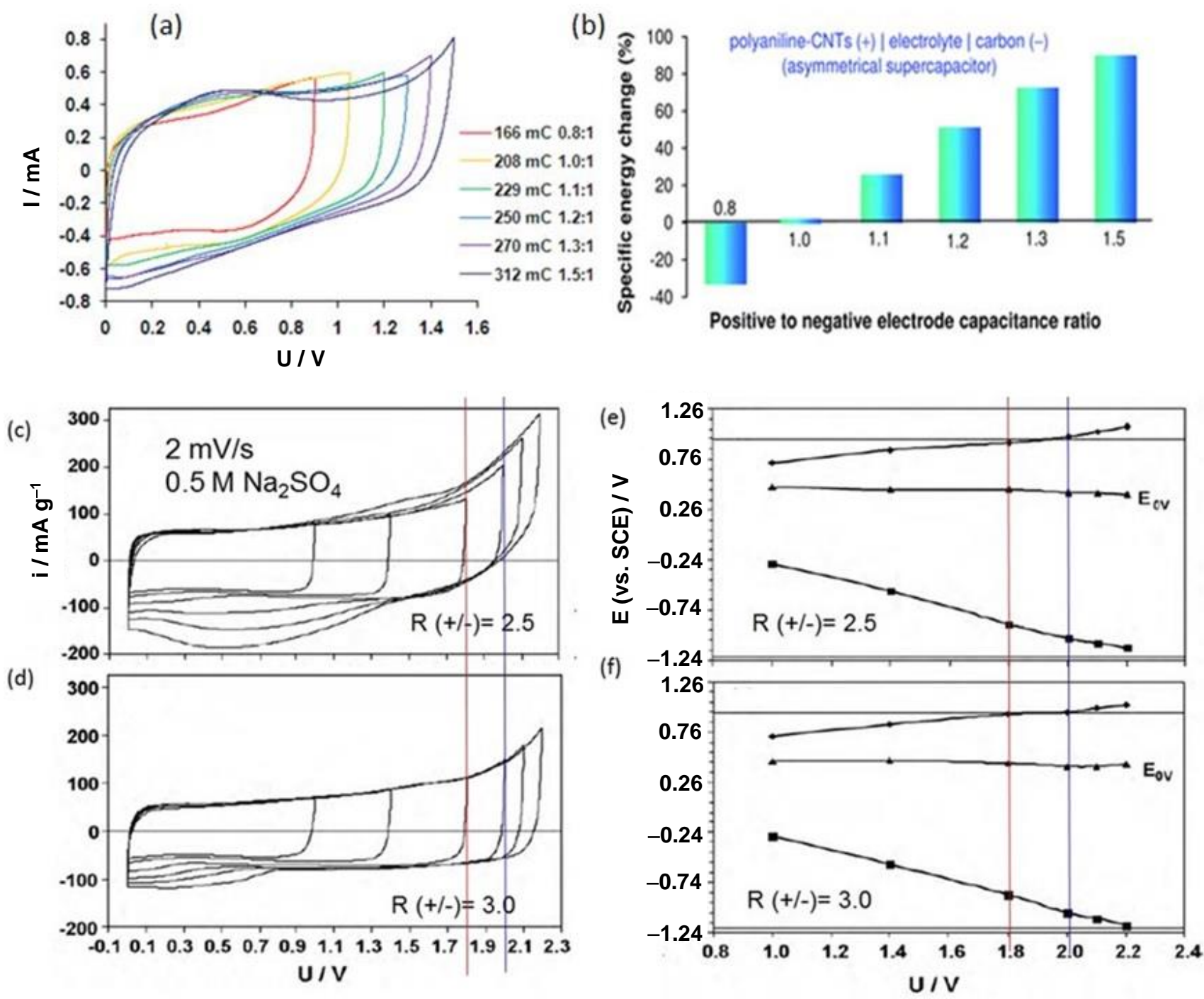

4

Figure 6: AECs with EDLC and pseudocapacitive electrodes. (a) CVs of (-) CMPB | $1.0 \mathrm{~mol} / \mathrm{L} \mathrm{H}_{2} \mathrm{SO}_{4}$ I PAn-CNT (+) at indicated $\mathrm{C}_{\mathrm{p}} / \mathrm{C}_{\mathrm{N}}$ ratios. (b) Energy change of the cell in (a) as a function of the $C_{\mathrm{P}} / C_{\mathrm{N}}$ ratio [36]. (c, d) $\mathrm{CVs}$ of (-) $\mathrm{AC}\left|0.5 \mathrm{~mol} / \mathrm{L} \mathrm{Na}_{2} \mathrm{SO}_{4}\right| \mathrm{MnO}_{2}-\mathrm{CNT}(+)$ with positrode to negatrode mass ratio, $\mathrm{R}(+/-)=2.5(\mathbf{c})$ and $3.0(\mathbf{d})$, respectively. (e,f) Plots of electrode potential against cell voltage for the cells in (c) and (d), respectively [41]. 
(a)

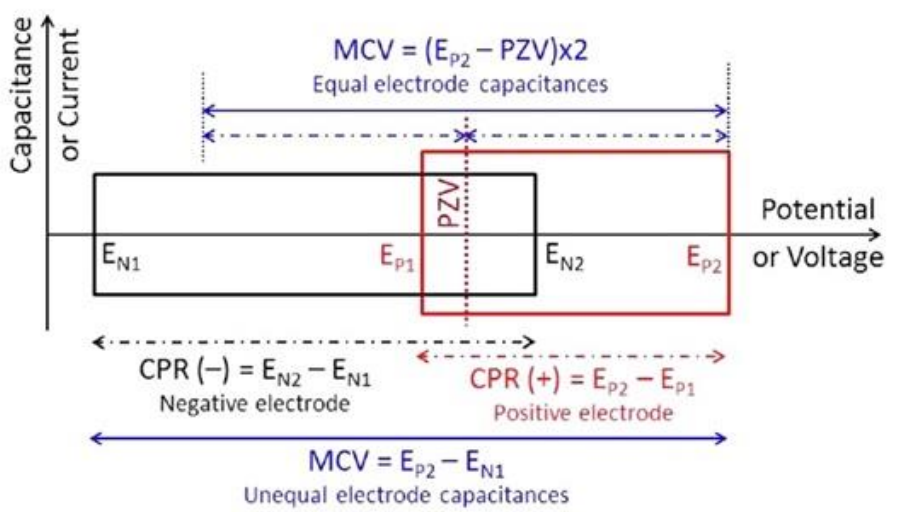

(b)

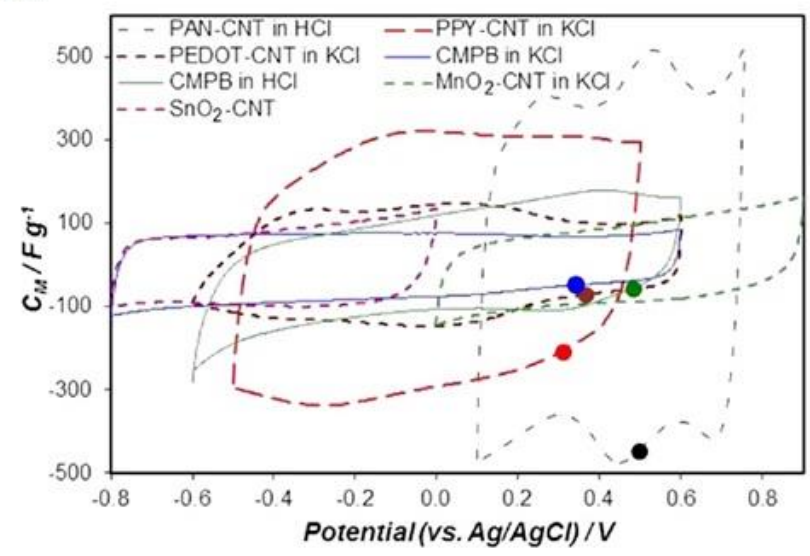

Figure 7: (a) Schematic illustration of capacitive electrodes in AECs with CPR(-) and CPR(+) being the capacitive potential range for the negatrode and positrode, respectively. (b) Stable capacitive potential range of some capacitive electrodes in aqueous electrolytes. The coloured circular dots refer to the open circuit potentials of the respective "electrode I electrolyte" interfaces after a rest time of $4 \mathrm{~h}$

10 [37].

11

12 


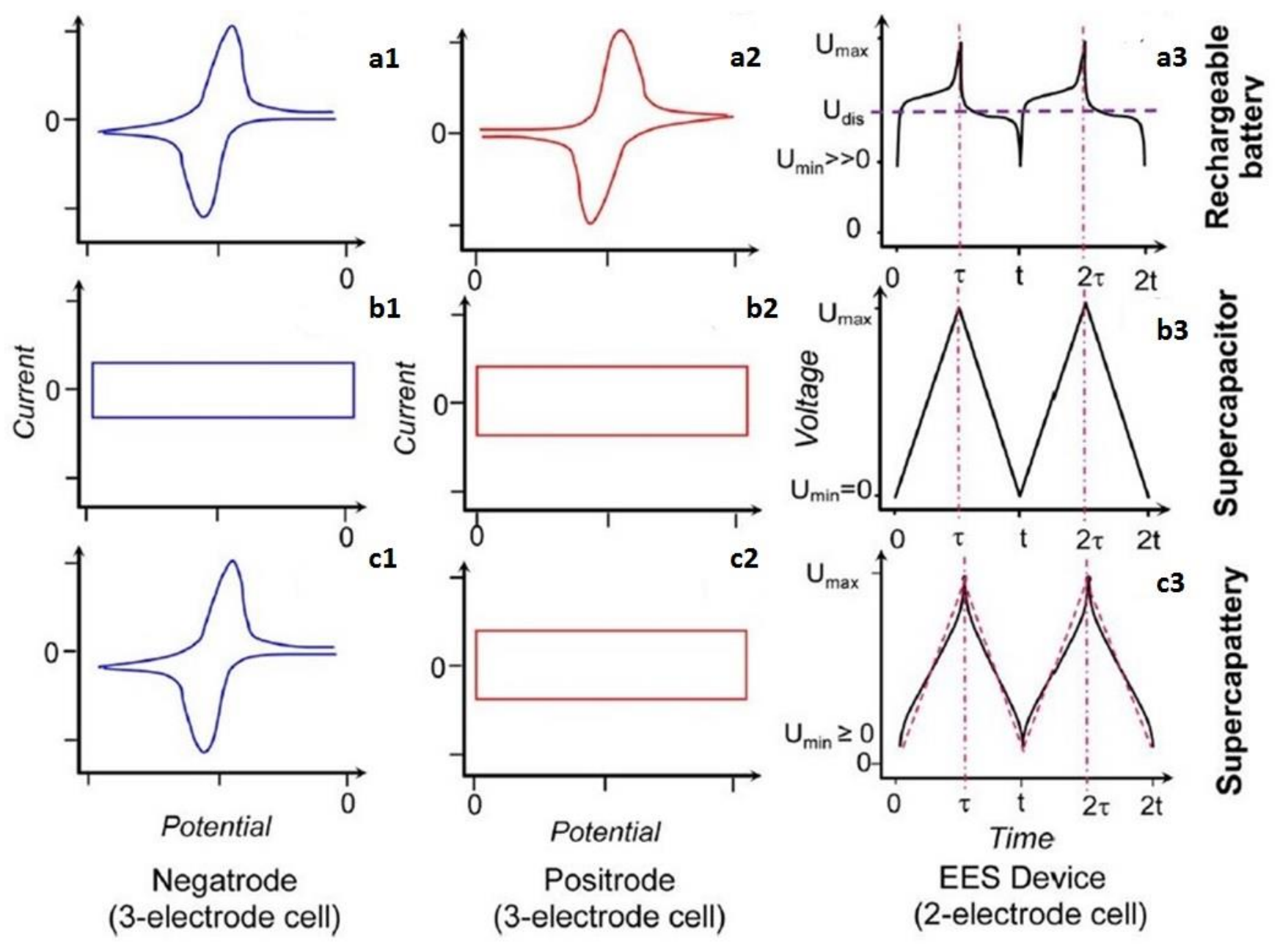

Figure 8: Schematic illustrations of $(\mathbf{1 , 2}) \mathrm{CVs}$ of positrode and negatrode in a three electrode cell, and (3) GCDs of the two electrode cell of (b) rechargeable battery, (c) supercapacitor, or (d) supercapattery. $U_{\max }$ and $U_{\min }$ : maximum and minimum cell voltages that can be reached during charging and discharging, respectively, without causing irreversible changes in the cell. $U_{\text {dis: }}$ average

9 discharging voltage. $\tau$ and $\mathrm{t}$ : end times of the first charging and discharging cycle, $\tau \geq(\mathrm{t}-\tau)$. $2 \tau$ and $2 \mathrm{t}$ :

10 end times of the second charging and discharging cycle, but not necessarily twice of $\tau$ and $t[11,25]$. 

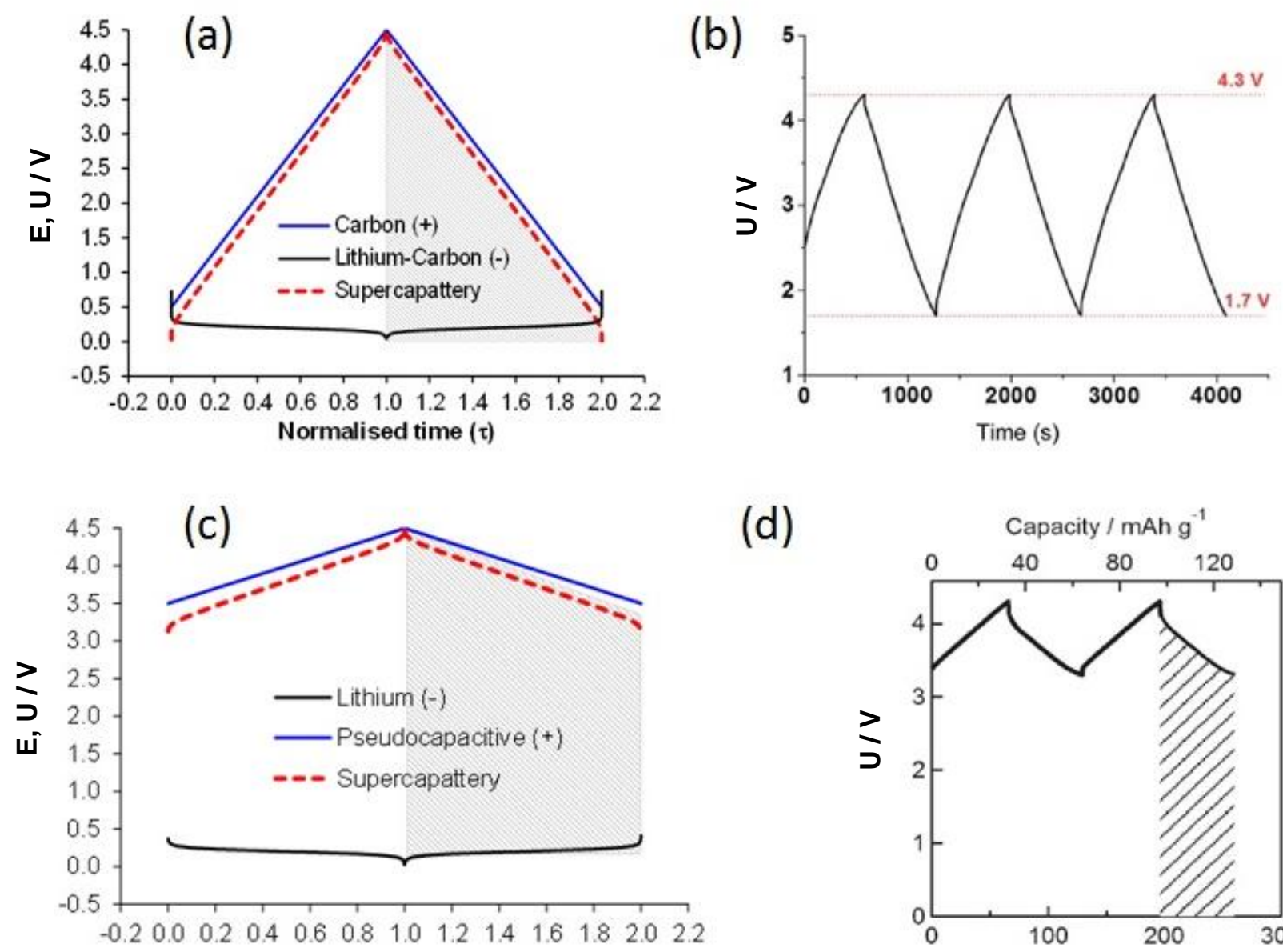

(d)

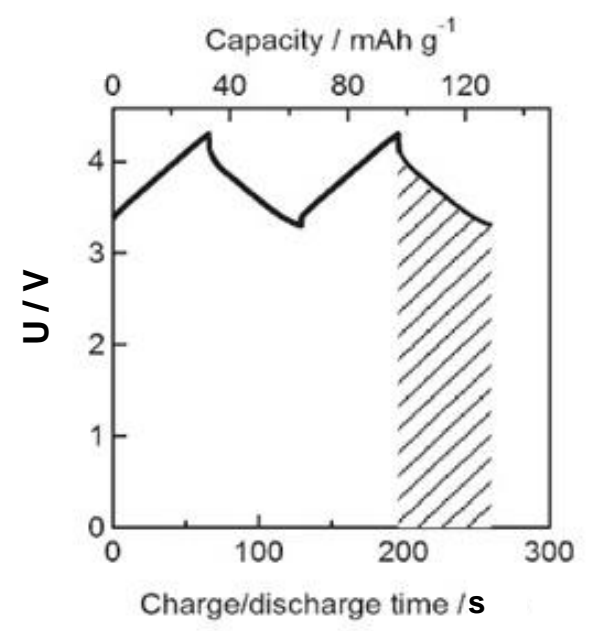

Normalised time $(\tau)$

(e)

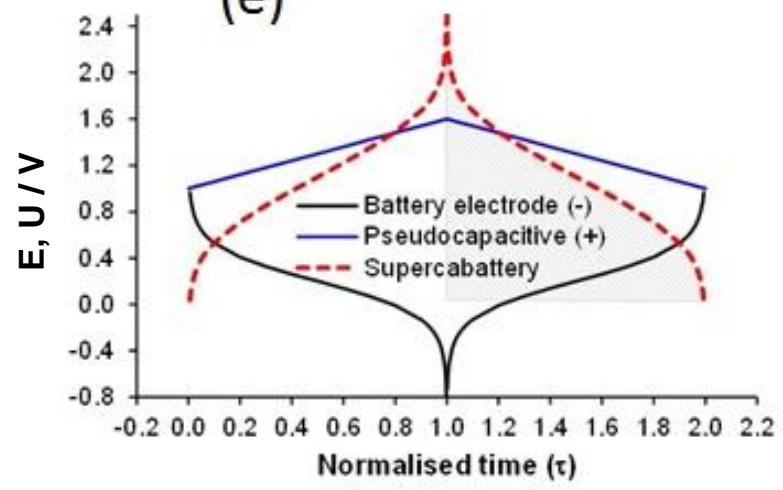

3 Figure 9: GCDs of the positrode, negatrode and cell of (a) the hypothetic supercapattery I with an 4 EDLC positrode and a $\mathrm{Li}$ or lithiated carbon negatrode [11], (b) the cell of (-) $\mathrm{Li}\left|\mathrm{LiClO}_{4}+\mathrm{IL}\right| \mathrm{AC}$ 5 (+) at $0.4 \mathrm{~A} / \mathrm{g}$ [74], (c) the hypothetic supercapattery II with a pseudocapacitive positrode and a Li or 6 lithiated carbon negatrode [11], (d) the cell of (-) Li | aqueous electrolyte I solid electrolyte $\mid \mathrm{MnO}_{2}(+)$ 7 at $0.255 \mathrm{~mA} / \mathrm{cm}^{2}$ [76], (e) the hypothetic supercabattery with pseudocapacitive positrode and battery 8 material negatrode [11]. 

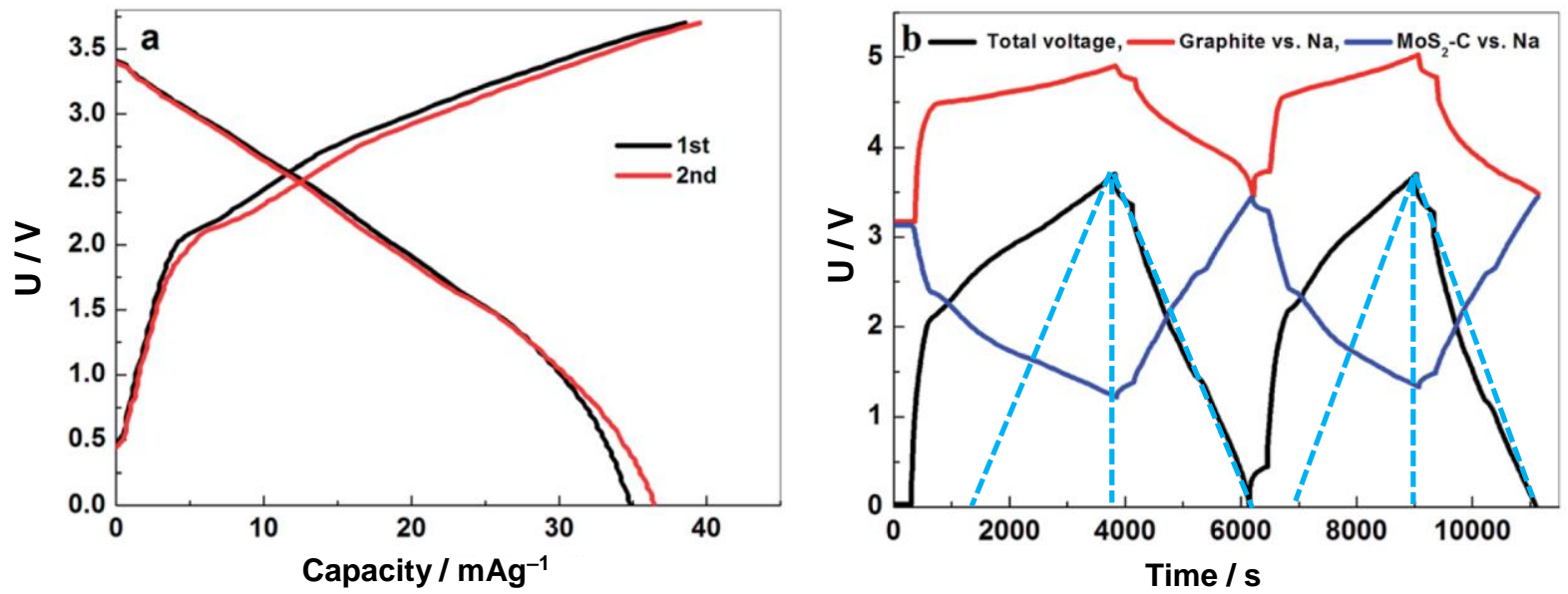

Figure 10: GCDs at $0.17 \mathrm{~A} / \mathrm{g}$ of a dual-ion cell of (-) $\mathrm{MoS}_{2}-\mathrm{C}\left|1.0 \mathrm{~mol} / \mathrm{L} \mathrm{NaPF}_{6}+\mathrm{PC}\right|$ graphite (+), showing (a) the cell voltage profiles in the initial charging-discharging cycles, and (b) the electrode potential (vs. $\mathrm{Na} / \mathrm{Na}^{+}$) and cell voltage profiles with the blue dashed linear lines to show the deviation from the ideal capacitive features based on the discharging behaviour of the cell [75]. 

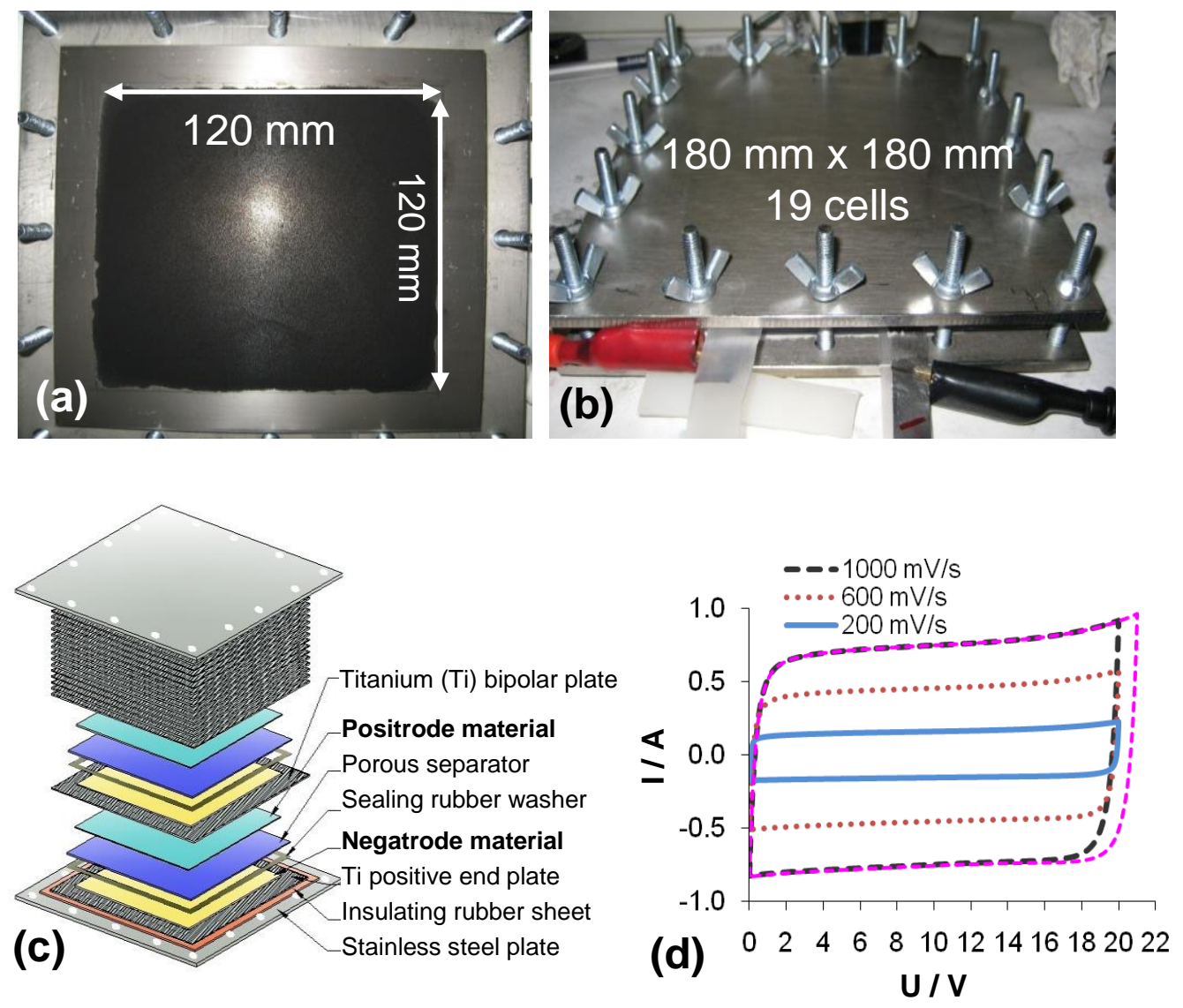

4 Figure 11: (a) PPy-CNT composite coating $(120 \mathrm{~mm} \times 120 \mathrm{~mm})$ on a bipolar Ti plate (current 5 collector) for the fabrication of a $20 \mathrm{~V}$ stack of 19 cells. (b) Top-view of the assembled stack of 19 cells. (c) Expanded illustration of the design of a stack of multiple AEC cells connected by bipolar current collector plates. (d) CVs of the stack in (b) at indicated voltage scan rates [78]. 

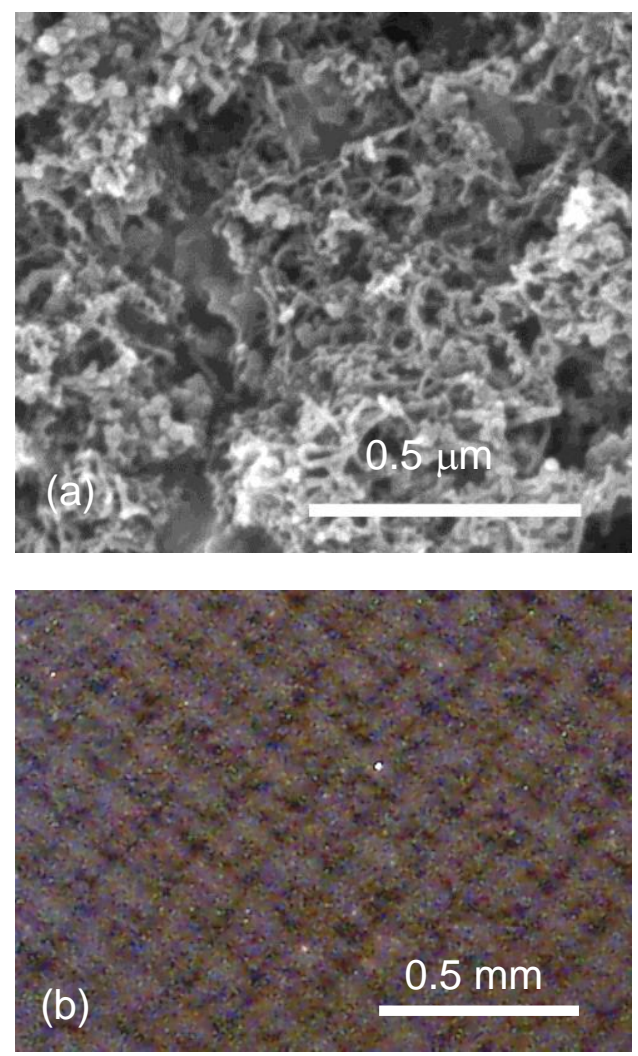

13

14

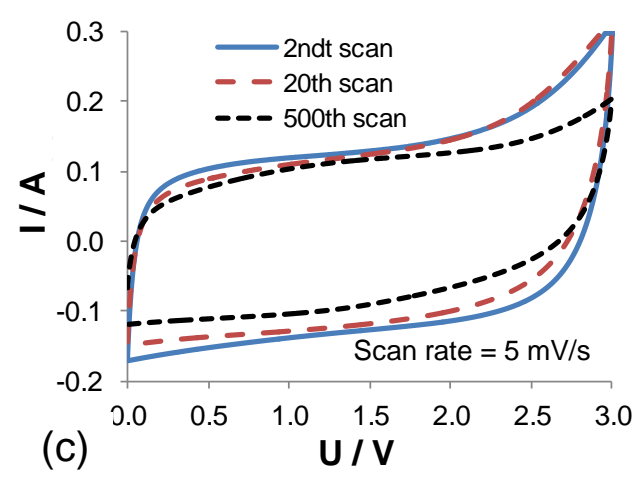

20 Figure 12. (a) SEM image of the PPy-CNT composite. (b) Top view of screen printed PPy-CNT 21 coating. (c) CVs recorded from a stack of two cells containing $3.0 \mathrm{~mol} / \mathrm{L} \mathrm{KCl}$ with screen printed $\mathrm{PPy}-$ 22 CNT on Ti bipolar (or end) plate and CMPB on porous membrane separator [79]. 